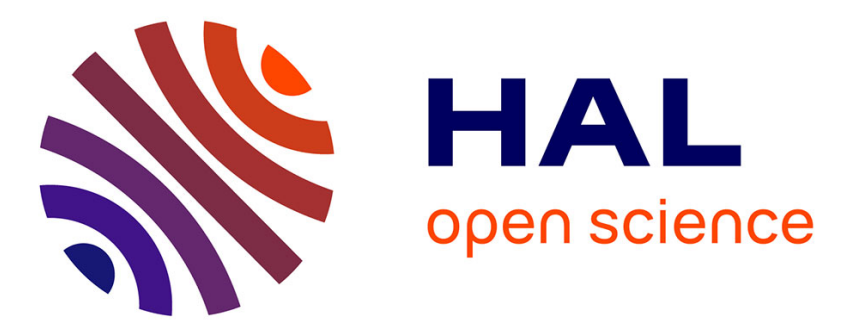

\title{
Tracking and specialization of high schools: heterogeneous effects of school choice
}

Olivier de Groote, Koen Declercq

\section{To cite this version:}

Olivier de Groote, Koen Declercq. Tracking and specialization of high schools: heterogeneous effects of school choice. Journal of Applied Econometrics, 2021, 36 (7), pp.898-916. 10.1002/jae.2856 . hal-03537880

\author{
HAL Id: hal-03537880 \\ https://hal.science/hal-03537880
}

Submitted on 20 Jan 2022

HAL is a multi-disciplinary open access archive for the deposit and dissemination of scientific research documents, whether they are published or not. The documents may come from teaching and research institutions in France or abroad, or from public or private research centers.
L'archive ouverte pluridisciplinaire HAL, est destinée au dépôt et à la diffusion de documents scientifiques de niveau recherche, publiés ou non, émanant des établissements d'enseignement et de recherche français ou étrangers, des laboratoires publics ou privés. 


\title{
Tracking and specialization of high schools: heterogeneous effects of school choice
}

\author{
Olivier De Groote* Koen Declercq ${ }^{\dagger}$
}

June 6,2020

\begin{abstract}
We analyze the impact of choosing an elite school on high school graduation in an early tracking system in Flanders (Belgium). Elite schools offer only an academic track, while most other schools offer multiple tracks. On average, students experience a 3.3 percentage point increase in the likelihood of obtaining a degree. We find that the effects are heterogeneous. On average, students who self-select into elite schools do not experience an effect, while students who do not choose an elite school would experience positive effects. Our results can be explained by different tracking decisions in both types of schools.
\end{abstract}

Keywords: elite schools, early tracking, marginal treatment effects

JEL: C31, I28

${ }^{*}$ Olivier De Groote: Toulouse School of Economics, University of Toulouse Capitole, email: olivier.degroote@tse-fr.eu. Corresponding author at Toulouse School of Economics, 1 Esplanade de L'Université, 31080 Toulouse Cedex 06, France.

†Koen Declercq: LEER, KU Leuven, IRES/LIDAM, UCLouvain and FNRS, email: koen.declercq@kuleuven.be. Naamsestraat 69, B-3000 Leuven, Belgium. We would like to thank Peter Arcidiacono, Estelle Cantillon, Bart Cockx, Jan De Loecker, Kristof De Witte, Arnaud Maurel, Erwin Ooghe, Jo Van Biesebroeck, Frank Verboven, seminar participants at KU Leuven, Duke University and Toulouse School of Economics and participants of the 2015 LEER workshop on Efficiency in Education in Leuven, the 2016 Belgian Day for Labor Economists in Antwerp, the 2016 EALE conference in Ghent, the 2017 LEER Workshop on Education Economics in Leuven, the 2017 SOLE conference in Raleigh, the 2017 IWAEE conference in Catanzaro, and the 2018 Matching in Practice Workshop in Cologne. Olivier De Groote acknowledges funding from the French National Research Agency (ANR) under the Investments for the Future (Investissements d'Avenir) program, grant ANR-17-EURE-0010. We would also like to thank the Flemish Ministry of Education for providing the dataset and the Research Foundation Flanders (FWO) for their financial support. 


\section{Introduction}

Completing secondary education is important for opportunities in life. Among the group of 25-34-year-olds in OECD countries, the unemployment rate is $14.8 \%$ for individuals who did not complete secondary education, but only $7.8 \%$ and $5.8 \%$ for individuals who completed secondary and higher education, respectively. Furthermore, high school dropouts earn only $78 \%$ of what workers earn who completed at most secondary education. Despite the importance of a high school degree for future success on the labor market, $16 \%$ of young adults in OECD countries drop out without obtaining a degree (OECD, 2018).

In this paper we study the causal and heterogeneous impact of choosing an elite school on completing secondary education. We define an elite school as a school that offers only the academic track. We use a rich administrative dataset of all entrants in secondary education in 2003 and 2004 in Flanders, the Dutch-speaking part of Belgium. 8\% of the students in our sample did not graduate from high school, which can have an important impact on their future labor market opportunities. In Belgium, unemployment among high school dropouts is particularly high. Among the group of 25-34-year-olds, the unemployment rate for high school dropouts is $22.7 \%$ but only $9.0 \%$ and $4.7 \%$ for individuals who completed secondary and higher education, respectively (OECD, 2018). ${ }^{1}$

In the second part of this paper, we study how the organization of the tracking system can explain our results. Many countries apply some form of tracking and group students by their ability and preferences. Countries can be classified according to two different types of tracking systems. The first type of countries like Austria, Belgium, Germany, Greece, Japan and the Netherlands split students into academic and vocational tracks. The second type of countries like the US, Canada, UK and New Zealand apply course-by-course tracking and allow students to choose the level of their courses instead. While tracking into different programs often happens between schools, course-by-course tracking is applied within schools (Chmielewski, 2014).

In Flanders, students are tracked into different programs around the age of 13 . The first year of secondary education consists of a comprehensive program and is open to all students who are qualified to attend secondary education. Students can also follow this program at the school of their choice as free school choice is legally enforced. In the following years, students specialize in a certain program, within a track. Programs can be categorized into four hierarchically ordered tracks. The academic track prepares students for academic

\footnotetext{
${ }^{1}$ For Flanders, statistics show that $27.6 \%$ of high school dropouts were still unemployed one year after leaving school in 2017, while this was only $9.3 \%$ and $3.5 \%$ for students graduating from secondary and higher education, respectively (VDAB, 2019).
} 
programs (at least four years) at university. ${ }^{2}$ Other tracks prepare for professional programs (three years) in tertiary education or for the labor market. As long as students perform well, they can choose from among all of the programs. If they fail some courses, they may be excluded from certain options in the following year. Alternatively, they may be required to repeat a year of study.

There exist several types of schools in Flanders. While elite schools offer only the academic track, most non-elite schools offer the academic track in combination with other tracks. While grouping students of different abilities into the same school is standard in countries that use course-by-course tracking, it is less often the case in systems that split students early in academic and vocational tracks. ${ }^{3}$ The supply of tracks within a specific school can affect study decisions if students prefer to stay in the same school. If schools offer programs in all tracks, tracking can occur within the same school. If schools specialize in one track, students may be less likely to choose the optimal track if it is not offered at this school. If students do not perform well, they can still switch to a lower track (downgrade) during their secondary education. Recent evidence shows that misallocated students can avoid the negative effects of early tracking by switching tracks when they are older (Dustmann et al., 2017). If more study options are available in the same school, it is possible that misallocated students are more likely to switch programs. Therefore, offering several tracks within a school can improve study outcomes by reducing switching costs. On the other hand, specialization in one track can have benefits in attracting a more homogeneous peer group or specialized teachers. It could also be more efficient if the school infrastructure is highly track-specific.

Enrollment in an elite school is a composite treatment. First, tracking decisions can be different in elite and non-elite schools due to a different supply of tracks. Second, elite schools attract students of higher ability and of higher socioeconomic status leading to a different peer group composition. Finally, there could be differences in grading standards as schools have some autonomy in deciding about grade progression. Notice that the Flemish government sets out common learning goals for students to achieve in each track and that these learning goals do not differ between elite and non-elite schools. This implies that students in the academic track in elite and non-elite schools follow the same curriculum.

To study the treatment effects of elite schools on high school graduation, we face the following two problems: (1) endogeneity because of non-random self-selection into elite schools

\footnotetext{
${ }^{2}$ Although there are almost no admission standards for higher education in Flanders, the tracks students follow in high school are important predictors of success at these institutions (Declercq and Verboven, 2015).

${ }^{3}$ Some other countries also have multi-track schools. See for example the "kooperative Gesamtschulen" in Germany (Mühlenweg and Puhani, 2010), or comprehensive schools in the Netherlands (Oosterbeek et al., 2020).
} 
and (2) heterogeneity in the effects. We address the first problem by using distance as an instrument for school choice. The policy of free school choice and the large availability of different schools within a neighborhood make distance a reasonable instrument for school choice in Flanders, conditional upon controlling for neighborhood characteristics. If the treatment effect differs between students because of unobserved characteristics, the conventional two stage least squares (2SLS) estimator is difficult to interpret, as, in general, it cannot be interpreted as an average treatment effect (ATE), average treatment effect on the treated (ATT) or average treatment effect on the non-treated (ATNT) (Heckman and Vytlacil, 2005).

We allow for heterogeneous treatment effects in different ways. First, we follow the framework of Heckman and Vytlacil (2005) and estimate Marginal Treatment Effects (MTEs) to compute average treatment effects. This requires enough observations in treated and nontreated states at each value of the unobserved cost of treatment. The richness of our data allows us to use standard semi-parametric estimation techniques to recover the ATT. We compare this estimate to an estimate that is derived from a potential outcome model that uses limiting functional form and distributional assumptions. This also gives us an estimate of the ATE and ATNT and illustrates how observable background characteristics can explain differences in treatment effects. Finally, we show how a factor structure, as proposed by Aakvik et al. (2005), allows us to identify distributional treatment effects: the percentage of students that would experience a positive or negative treatment effect from elite schools.

We obtain the following main findings. On average, students are more likely to obtain a high school degree if they start at an elite school. We obtain a significantly positive ATE of 0.033, which implies that choosing an elite school, on average, increases the probability of graduating from high school by 3.3 percentage points. We also find important heterogeneity in the treatment effect, reflected in a small and statistically insignificant ATT and a large ATNT of 5.1 percentage points. We can therefore conclude that the students who do not choose elite schools would benefit most from treatment.

Next, we find that the average treatment effects still mask a lot of heterogeneity. We find more positive effects for students who had repeated a grade before starting high school and students with a low-educated mother. These are characteristics that make students less likely to choose an elite school. This finding is in line with the above finding, that students who are expected to gain the most from elite schools are less likely to start at an elite school. Furthermore, our results indicate that there is heterogeneity within both groups of treated and non-treated students, with a substantial fraction gaining and suffering from elite schools in both groups.

Finally, we study how the tracking of students is influenced by the type of school and whether a different tracking in elite and non-elite schools explains the heterogeneity we 
find. We therefore extend the potential outcomes framework by modeling the track choice in the second year of high school. This model shows that choosing the academic track raises the probability of graduating from high school. Moreover, elite schools encourage students to study the academic track, but primarily for non-treated students. This is because most treated students would choose an academic track in any school. At the same time, treated students are very reluctant to leave an elite school and aim for a lower ranked track when they do not perform well. Consequently, this puts them at a risk of dropping out. We provide further evidence for this explanation by applying our main model to a new outcome: downgrading, that is, a switch to a lower track during their studies. We also find here that elite schools make students less likely to downgrade, especially those with the highest preferences and the least positive or most negative treatment effects on high school completion.

Our findings have important implications for policy. Encouraging students to start at elite schools can raise the overall degree completion in secondary education. However, there is a lot of heterogeneity in the effect of treatment within both the group of treated and nontreated students and the reverse selection on gains shows that students are not optimally choosing their school. An optimal policy would therefore allocate students to the type of school that benefits them most. Students from disadvantaged backgrounds who have the ability to pursue an academic track should be encouraged to start at an elite school. Information provision and more active counseling could help students choosing their school. Furthermore, it is important to encourage students with a high preference for elite schools to consider another school when they do not perform well in the academic track (such as students from a high socioeconomic background).

Our paper contributes to three strands of literature. First, we contribute to the literature on the effects of elite schools. Similar to our study, Clark and Del Bono (2016), Dustmann et al. (2017), Guyon et al. (2012) and Oosterbeek et al. (2020) analyze the effects of attending a school that specializes in academic programs. Pop-Eleches and Urquiola (2013) and Abdulkadiroğlu et al. (2014) also study the effects of elite schools but define these schools on the basis of the quality of their peers. Nevertheless, also in our context, elite schools attract a group of students who come from families with a stronger socioeconomic background and generally perform better in school. In contrast to previous studies, we study the observed and unobserved heterogeneity in the treatment effect. We characterize the degree of heterogeneity by comparing the ATT and ATNT, but also the percentage of students who gain and loose. This shows that averages can mask large differences between students. Moreover, identification strategies in other papers identify an average treatment effect for specific groups in the population. Our results show that the large degree of heterogeneity in 
treatment effects makes it difficult to extrapolate these results to the total population. ${ }^{4}$ We also show how the supply of tracks in each type of school can explain heterogeneity in the effect.

Second, we contribute to the literature on the impact of educational tracking. Several papers have looked at the consequences of tracking students at an early age (Fu and Mehta (2018), Hanushek and Woessmann (2006), Pekkarinen et al. (2009), Roller and Steinberg (2020)). ${ }^{5}$ Other characteristics of tracking systems remain largely unexplored, with the exception of Cockx et al. (2018), De Groote (2019) and Dustmann et al. (2017) who investigate the impact of being able to switch tracks at a later age. We contribute to this literature by comparing the impact of tracking between and within schools.

Finally, we apply advances in the econometric literature on estimating treatment effects proposed by Heckman and Vytlacil (2005) and Aakvik et al. (2005). We are able to identify semi-parametric MTE estimates to derive the ATT and compare it with the results of a model that estimates a potential outcomes model with functional form and distributional assumptions. ${ }^{6}$ Imposing these assumptions also gives us additional insights in the degree of heterogeneity of the treatment effect. We extend the potential outcomes model and also model an intermediate choice, the high school track. Simultaneously modeling both choices allows us to study how school choice influences track choice and provides insight into the underlying mechanism that explains the effects of elite school attendance.

The paper is organized as follows. We start by providing an overview of secondary education in Flanders and introduce our dataset. Next, we discuss the empirical framework in Section 3 and discuss the validity of our instrument in Section 4. Section 5 discusses the main results, Section 6 the underlying mechanism and Section 7 concludes. Online Supporting Information Appendices A-D provide details about the construction of the dataset, sensitivity analyses, a discussion on the role of control variables and additional tables and figures.

\footnotetext{
${ }^{4}$ Oosterbeek et al. (2020) study observed heterogeneity in the treatment effect based on test scores before the start of high school. Their study considers only students who were qualified to enter the highest track and decided to apply for an elite school. We look at decisions before tracking occurs and we characterize both observed and unobserved heterogeneity in the treatment effect.

${ }^{5}$ See also Cummings (2017) and Duflo et al. (2011) for evidence in developing countries.

${ }^{6}$ MTEs are usually only identified for a subset of individuals, such that it is not possible to estimate the ATE, ATT or ATNT nonparametrically. See, for example, Doyle (2007 and 2008) and Galasso and Schankerman (2015). Other papers rely on parametric assumptions on the shape of the MTE curve or the underlying behavioral model to improve common support or obtain sufficiently precise estimates (Carneiro et al. (2011), Carneiro et al. (2016), Cornelissen et al. (2018), Basu et al. (2007), and Nybom (2017)).
} 


\section{Secondary education in Flanders}

In this section we discuss the institutional context in Flanders and show some descriptive statistics about enrollment and study outcomes for students choosing elite and non-elite schools.

\subsection{Institutional overview}

Flanders is the Dutch-speaking part of Belgium, located in the North. It consists of approximately $60 \%$ of the population of 11 million inhabitants. ${ }^{7}$ After finishing primary school, students enroll in secondary education, usually at the age of 12. Students can choose between all schools in Flanders since school choice is not geographically restricted and free school choice is law-enforced. ${ }^{8}$ In the first year of secondary education (grade 7 ), almost all students start in a comprehensive program. A small proportion starts in a vocational-preparatory program. As these students often did not successfully complete primary education, we do not consider this group in our analysis.

After the first year, students can choose between programs in four hierarchically ordered tracks. ${ }^{9}$ The academic track is the highest track and prepares students for academic programs in higher education (mostly four- or five-year programs). The technical track and the artistic track prepare students for professional programs in higher education (mostly three-year programs) or for the labor market. Students can also choose the vocational track, which prepares them for the labor market. Both students' preferences and scores in the first year determine the track. If they perform well, they can choose between all tracks. Students who fail on some courses may be excluded from certain programs or tracks. If they fail on too many important courses, they can also be required to repeat a grade. ${ }^{10}$ While mobility

\footnotetext{
${ }^{7}$ We include all students going to Flemish schools in the analysis. Most of the schools are located in the monolingual region of Flanders, but a few of them are located in the bilingual (French-Dutch) "BrusselsCapital Region", where Flemish families are a minority group.

${ }^{8}$ Capacity constraints were uncommon, but we cannot exclude that some schools were oversubscribed. The Belgian constitution, however, protects free school choice and prevents schools from cream skimming. If the school is capacity constrained, it must add students to a waiting list, and if places become available, it must respect the order of this list.

${ }^{9}$ Officially the distinction between tracks exists only from the third year on (grade 9). However, at the start of the second year, students decide on elective courses that prepare them for a particular track. We therefore classify tracks from the second year on.

${ }^{10}$ At the end of each year, students obtain a certificate, based on their scores. They obtain an A-certificate if they succeeded in all major courses. They can then move on to the next grade and continue the same program. If they did not succeed in all courses, they might obtain a C-certificate which implies that they have to repeat all courses of the previous grade. There is also a third possibility: a B-certificate. This implies
} 
between tracks is generally possible, we observe almost only downward mobility; that is, students moving from the academic track to the technical or artistic tracks, and from the technical or artistic tracks to the vocational track. ${ }^{11}$ Note that this mobility is not always due to the restrictions of continuing in the same track but often results from a choice by students or their parents: they want to avoid failing too many courses and thereby risk accumulating a study delay in the future.

For each study program in each grade, the Flemish government sets out common learning goals for students to achieve, and schools organize their curriculum accordingly. The supply of these programs differs considerably between schools. Some schools specialize and offer programs in only one track, while other schools offer programs in multiple tracks. According to the tracks offered at schools, we can classify schools into two types. The first type of schools are elite schools. They offer only programs in the academic track. The second type of schools are non-elite schools. Most non-elite schools are multi-track schools and offer programs in the academic track together with programs in other tracks. However, some non-elite schools offer only programs in the technical, artistic and/or vocational track. ${ }^{12}$ Note that tracking decisions can be different in elite and non-elite schools because students in elite schools are required to switch to another school when they want to downgrade from the academic track. Even though students are free to switch between schools, it is likely that many of them prefer not to.

\section{$2.2 \quad$ A first look at the data}

We use a rich dataset provided by the Flemish Ministry of Education. We observe all students who started in the comprehensive program in secondary education in 2003 and $2004{ }^{13}$ We follow these students in secondary education and observe them during six years if they graduate within the minimal duration of the program or during nine years at most if they graduate after some delay. For every school year, we observe their school and program.

that they can move on to the next grade but only if they switch to a lower-ranked program. Alternatively, they can decide to repeat a grade instead.

${ }^{11}$ Only mobility from the vocational track to other tracks is not allowed but, in general, it is also difficult to move upwards from other tracks because students do not have the prerequisites for courses in the higher tracks.

${ }^{12}$ Our results do not change when we exclude the second type of non-elite schools from the analysis (see Supporting Information Appendix B).

${ }^{13}$ There are 144,873 students in these cohorts in our dataset. We keep the 121,746 students who start in the comprehensive program. We then remove some students for whom we do not observe characteristics or location to end up with a database of 111,571 students. Supporting Information Appendix A provides more details about the data selection process. 
We also observe when they obtain a high school degree and the years of study delay.

Table 1 summarizes the characteristics of students and their neighborhood in the two types of schools. It shows that $26.7 \%$ of all students start at an elite school. $48.6 \%$ of the students starting at elite schools are boys, while this is $49.9 \%$ at non-elite schools. Students who had repeated at least one year before starting at secondary education are less likely to choose an elite school. Grade repetition can be interpreted as a proxy for ability because students who do not meet the minimum standards can be required to repeat a grade during kindergarten or primary education. Socioeconomic status also determines school choice. Disadvantaged students are less likely to start at elite schools. The most notable effect is for the educational level of the mother. In elite schools, $55.8 \%$ of students has a mother with a higher education degree, while this is only $32.4 \%$ in non-elite schools.

The following panel shows neighborhood characteristics at the level of the municipality and at the level of the statistical sector. In Belgium, each municipality is divided into several statistical sectors. ${ }^{14}$ Statistical sectors are created in such a way that they split each municipality into homogeneous neighborhoods. Aggregate characteristics at the level of the statistical sector thus reflect the residential neighborhood, while characteristics at the level of the municipality capture amenities in a broader region. Both types of characteristics are important because they control for social segregation in specific neighborhoods. Most neighborhood characteristics are measured in 2001, before students enroll in secondary education. $^{15}$

Table 1 shows that students who attend elite schools live in municipalities with a higher median income. This difference is larger at the level of the statistical sector. This can be explained by the fact that statistical sectors are more homogeneous than municipalities. The share of individuals with the Belgian nationality in the neighborhood is similar for students attending elite and non-elite schools. Students attending elite schools live in statistical areas where $29.7 \%$ of the population has a degree in higher education, while this is only $25.1 \%$ for students attending non-elite schools. Finally, average population density is higher for students attending elite schools because relatively more elite schools are located in cities. ${ }^{16}$ We will control for these characteristics throughout the paper. Furthermore, we will control for fixed effects for each of the five provinces and for each level of urbanization of the

\footnotetext{
${ }^{14}$ Belgium consists of 581 municipalities and 19,781 statistical sectors (Vademecum Statistische sectoren, 2012). Statistical sectors have a surface of $1.5 \mathrm{~km}^{2}$ and 539 inhabitants, on average.

${ }^{15}$ Income is measured in 2004 but since all students would still be required to attend school at this time, there is no problem of reverse causality.

${ }^{16}$ Note that population density at the statistical sector and at the level of the municipality are two different measures that cannot be compared. A lower average population density at the level of the municipality can be explained by the fact that there are large statistical sectors with few inhabitants.
} 
Table 1: Enrollment in elite and non-elite schools

\begin{tabular}{|c|c|c|c|}
\hline & & Elite school & Non-elite school \\
\hline \multicolumn{2}{|l|}{ Total enrollment } & $26.7 \%$ & $73.3 \%$ \\
\hline \multicolumn{4}{|l|}{ Characteristics of students } \\
\hline \multirow[t]{2}{*}{ Gender } & Male & $48.6 \%$ & $49.9 \%$ \\
\hline & Female & $51.4 \%$ & $50.1 \%$ \\
\hline \multirow[t]{2}{*}{ Repeated during primary school } & Yes & $6.0 \%$ & $13.1 \%$ \\
\hline & No & $94.0 \%$ & $86.9 \%$ \\
\hline \multirow[t]{3}{*}{ Degree of the mother } & Higher education degree & $55.8 \%$ & $32.4 \%$ \\
\hline & High school degree & $32.8 \%$ & $43.1 \%$ \\
\hline & No high school degree & $11.4 \%$ & $24.5 \%$ \\
\hline \multirow[t]{2}{*}{ Language at home } & Dutch & $94.3 \%$ & $95.1 \%$ \\
\hline & Other language & $5.7 \%$ & $4.9 \%$ \\
\hline \multirow[t]{2}{*}{ Household income } & High income $^{a}$ & $85.9 \%$ & $78.5 \%$ \\
\hline & Low income & $14.1 \%$ & $21.5 \%$ \\
\hline \multicolumn{4}{|c|}{ Neighborhood characteristics of students (average) } \\
\hline \multirow{2}{*}{$\begin{array}{l}\text { Median household income } \\
\text { (in } 1000 \text { euro) }\end{array}$} & Municipality & 19.9 & 19.7 \\
\hline & Statistical sector & 20.8 & 20.1 \\
\hline \multirow[t]{2}{*}{ Belgian nationality } & Municipality & $95.6 \%$ & $95.8 \%$ \\
\hline & Statistical sector & $96.0 \%$ & $96.1 \%$ \\
\hline \multirow[t]{2}{*}{ Higher education degree } & Municipality & $28.0 \%$ & $25.4 \%$ \\
\hline & Statistical sector & $29.7 \%$ & $25.1 \%$ \\
\hline \multirow[t]{2}{*}{ High school degree } & Municipality & $29.6 \%$ & $30.2 \%$ \\
\hline & Statistical sector & $29.6 \%$ & $30.5 \%$ \\
\hline \multirow[t]{2}{*}{ No high school degree } & Municipality & $42.4 \%$ & $44.4 \%$ \\
\hline & Statistical sector & $40.7 \%$ & $44.4 \%$ \\
\hline \multirow{2}{*}{$\begin{array}{l}\text { Population density (in } 100 \\
\text { inhabitants per } \mathrm{km}^{2} \text { ) }\end{array}$} & Municipality & 8.2 & 6.6 \\
\hline & Statistical sector & 26.7 & 23.4 \\
\hline \multicolumn{4}{|l|}{ Distance to school ( $k m$, average) } \\
\hline \multicolumn{2}{|l|}{ Distance to closest elite school } & 3.3 & 5.4 \\
\hline \multicolumn{2}{|l|}{ Distance to closest non-elite school } & 2.4 & 2.3 \\
\hline \multicolumn{2}{|l|}{ Observations } & 29,762 & 81,809 \\
\hline
\end{tabular}

Note: 111,571 students starting secondary education in 2003 or 2004. Percentages are conditional on school choice. Median household income is measured in 2004 and other neighborhood characteristics are measured in 2001.

${ }^{a}$ Not eligible for study grant. 
municipality (using four categories). We also observe the location of students and schools. ${ }^{17}$ Average distances to both types of schools are small (2 to $5 \mathrm{~km}$ ) and the average distance to elite schools is smaller for the group of students actually choosing an elite school $(3 \mathrm{~km}$ instead of $5 \mathrm{~km}) .^{18}$

Table 2 shows the track choice in the second year and the outcome variables that we consider in the analysis. $93.6 \%$ of students who started at an elite school enrolled in the

Table 2: Track choice and study outcomes by initial school choice

\begin{tabular}{lcc}
\hline & Elite school & Non-elite school \\
\hline Academic track in grade 8 & $93.6 \%$ & $55.3 \%$ \\
High school diploma & $94.3 \%$ & $90.8 \%$ \\
High school diploma without study delay & $77.5 \%$ & $70.0 \%$ \\
Downgrading $^{a}$ & $27.1 \%$ & $35.5 \%$ \\
& & \\
Observations & 29,762 & 81,809 \\
\hline
\end{tabular}

Note: 111,571 students starting secondary education in 2003 or 2004. Percentages are conditional on school choice.

${ }^{a}$ Dummy variable equal to 1 when a student switches from a high to a low track during secondary education.

academic track in the second year of secondary education, while this is only $55.3 \%$ for students starting in non-elite schools. Note that students in elite schools have to leave the school if they want to start in a non-academic track.

Our main outcome variable is graduating from high school. We define this variable by looking at the data for these students until 2011 (cohort of 2003) and 2012 (cohort of 2004). Since it takes a minimum of six years to graduate from high school, we allow for up to three years of study delay. ${ }^{19}$ Students who started at elite schools perform better: $94.3 \%$ of the students who started in their first year at an elite school graduate from high school, while

\footnotetext{
${ }^{17}$ We observe the location of the students at the level of the statistical sector. We compute the distance from the center of the statistical sector to the exact location of the school.

${ }^{18}$ Both types of schools are within commuting distance for almost all students. Distance to a non-elite school is $2.4 \mathrm{~km}$, on average, with a standard deviation of only $1.9 \mathrm{~km}$. Distances to elite schools are greater: $4.8 \mathrm{~km}$, on average, with a standard deviation of $3.8 \mathrm{~km}$. Nevertheless, at the 95th percentile, there is still a reasonable distance to travel of $11.6 \mathrm{~km}$.

${ }^{19} 0.3 \%$ of the students are still enrolled in secondary education in the last year of our dataset and have not yet obtained their degree at the end of this year. We consider them as drop-outs in the main analysis. We obtain similar results when omitting these students or assigning them to the group of high school graduates (see Supporting Information Appendix B).
} 
only $90.8 \%$ of the students who started at a non-elite school eventually graduate. We also consider an alternative outcome: graduating from high school without a study delay (i.e., within the theoretical duration of six years). Study delay is common because only $77.5 \%$ of students starting in elite schools and $70.0 \%$ of students starting in a non-elite school graduate on time. Finally, downgrading (i.e., a switch from a higher to a lower track) is more common in non-elite schools: $35.5 \%$, compared to only $27.1 \%$ in elite schools. As for the initial track choice, downgrading also requires switching to a different school for students in elite schools.

In general, we conclude that students choosing elite schools are more likely to start at the academic track, less likely to downgrade and more likely to graduate from high school, but enrollment in elite schools is not random. Therefore, we need to control for self-selection in order to investigate the causal effects of an elite school.

\section{Empirical framework}

We study the causal effect of starting at an elite school on obtaining a high school degree. To address the potential self-selection of high ability students in elite schools, we use distance as an instrument for school choice. In this section, we first specify a standard potential outcome framework. We then discuss how to use this model to build a semi-parametric estimator for the average treatment effects, using the Marginal Treatment Effect (MTE) framework of Heckman and Vytlacil (2005). ${ }^{20}$ Next, we show how parametric and distributional assumptions can overcome common support problems of the semi-parametric approach and how the factor structure of Aakvik et al. (2005) provides additional insights into the distribution of treatment effects.

\subsection{Potential outcomes}

Let $Y_{1 i}$ be the study outcome of student $i$ in the case of treatment, starting at an elite school $\left(D_{i}=1\right)$, and $Y_{0 i}$ the outcome of student $i$ if he starts at a non-elite school $\left(D_{i}=0\right)$. For each student $i$, we observe only the realized outcome $Y_{i}$ in the observed state:

$$
Y_{i}=D_{i} Y_{1 i}+\left(1-D_{i}\right) Y_{0 i}
$$

with $Y_{1 i}=\mu_{1}\left(X_{i}, U_{1 i}\right)$ the outcome in case of treatment (going to an elite school), and $Y_{0 i}=\mu_{0}\left(X_{i}, U_{0 i}\right)$ in the case of no treatment. $X_{i}$ is a vector of observed characteristics of students and $U_{0 i}$ and $U_{1 i}$ are unobserved random variables.

\footnotetext{
${ }^{20}$ See also Cornelissen et al. (2016) for an overview on how to apply this method.
} 
Let selection into treatment be given by

$$
D_{i}=1\left(V_{i} \leq \mu_{D}\left(X_{i}, Z_{i}\right)\right)
$$

with 1() an indicator function $=1$ if the expression between brackets is true, $\mu_{D}\left(X_{i}, Z_{i}\right)$ an arbitrary function of observed characteristics $X_{i}$ and an instrument $Z_{i}$. $V_{i}$ is the unobserved cost of treatment for student $i$ with $F_{V}$ its cumulative distribution function. We can then apply a probability normalization such that $D_{i}=1\left(U_{D i} \leq P\left(X_{i}, Z_{i}\right)\right)$ with $P\left(X_{i}, Z_{i}\right) \equiv$ $F_{V}\left(\mu_{D}\left(X_{i}, Z_{i}\right)\right)$ the propensity score and $U_{D i} \equiv F_{V}\left(V_{i}\right)$ an unobserved cost of treatment that is uniformly distributed on the unit interval, regardless of the distribution of $V .{ }^{21}$ Our main interest is in the Average Treatment Effect: $A T E=E\left[Y_{1 i}-Y_{0 i}\right]$, the Average Treatment effect on the Treated: $A T T=E\left[Y_{1 i}-Y_{0 i} \mid D_{i}=1\right]$ and the Average Treatment effect on the Non-Treated: $A T N T=E\left[Y_{1 i}-Y_{0 i} \mid D_{i}=0\right]$.

\subsection{Semi-parametric estimation of average treatment effects}

To allow for heterogeneous effects, we follow the framework of Heckman and Vytlacil (2005) by using Marginal Treatment Effects (MTEs) as a building block for constructing the ATT, ATE and ATNT. The MTE is the effect of attending an elite school for students with observable characteristics $X_{i}=x$ and unobserved cost of treatment $U_{D i}=u_{D}$ :

$$
\operatorname{MTE}\left(x, u_{D}\right)=E\left[Y_{1 i}-Y_{0 i} \mid X_{i}=x, U_{D i}=u_{D}\right]
$$

We can interpret the treatment effect at low values of $u_{D}$ as the effect for students who have a low unobserved cost; that is, a high unobserved preference for attending an elite school. The effect at high values is the effect for students with high unobserved costs, or low unobserved preferences. A weighted average of the MTEs then yields estimates of the ATE, ATT and ATNT (Heckman and Vytlacil, 2005).

As explained in Cornelissen et al. (2016), the minimal set of assumptions we need for MTE estimation is similar to the set of assumptions needed for the LATE interpretation of the 2SLS estimator (Imbens and Angrist, 1994). In section 4 we discuss the validity of these assumptions in the context of our application based on empirical evidence. In the rest of the paper, we maintain the following assumptions on the instrument $Z_{i}$ :

Condition 1 (Relevance) $Z_{i}$ is a random variable such that the propensity score $P\left(X_{i}, Z_{i}\right)$ is a nontrivial function of $Z_{i}$.

\footnotetext{
${ }^{21}$ While a specific distribution is not imposed, we do require the distribution to be absolutely continuous with respect to the Lebesgue measure.
} 
Condition 2 (Independence) $\left(U_{0 i}, U_{1 i}, U_{D i}\right)$ are independent of $Z_{i}$ conditional on $X_{i}$.

The first condition assures that the instrument is relevant in the school choice. The second condition assures that the instrument has no direct impact on study outcomes. Vytlacil (2002) also notes that the selection model in (2) is equivalent to the monotonicity condition of the LATE literature. In our context, this means that students should perceive distance to school as a cost and not as a benefit.

Estimation of the MTE can then proceed using local IV by determining how $Y_{i}$ changes with $P\left(X_{i}=x, Z_{i}=z\right)$ in small neighborhoods around each value of $P(x, z)$ (Heckman and Vytlacil, 1999). To identify the entire $\operatorname{MTE}\left(x, u_{D}\right)$ function, we need common support, i.e. we need sufficient observations of both treated and non-treated students at each value of $P(x, z)$. To achieve this, we follow a semi-parametric approach where the control variables enter the outcome equation linearly, but the functional form of the MTE curve (across control variables) is not restricted (see Section 4.3 in Cornelissen et al. (2016)).

In Section 4, we show that we can identify $\operatorname{MTE}\left(x, u_{D}\right)$ for all $u_{D} \leq 0.81{ }^{22}$ This allows us to interpret how the costs of treatment relate to treatment outcomes for students with low costs, or high preferences, of attending an elite school. This is sufficient to estimate the ATT because the weights in the calculation of the ATT are 0 for $u_{D}>0.81 .^{23}$ Nevertheless, this approach does not allow estimation of the ATNT and ATE with our data. We therefore discuss a model that introduces functional form and distributional assumptions.

\subsection{Parametric estimation of average treatment effects}

We follow Manski et al. (1992) and impose parametric and distributional assumptions to model treatment and potential outcomes. The structure is sufficiently flexible to allow for heterogeneous treatment effects and does not impose the structure of a Roy model, that is, students do not need to select on gains of treatment. We use the following functional form assumptions:

$$
\begin{aligned}
D_{i} & =1\left(\gamma Z_{i}+\delta X_{i}-V_{i} \geq 0\right), \\
Y_{0 i} & =1\left(\beta_{0} X_{i}-U_{0 i} \geq 0\right), \\
Y_{1 i} & =1\left(\beta_{1} X_{i}-U_{1 i} \geq 0\right),
\end{aligned}
$$

\footnotetext{
${ }^{22}$ We estimate the model in STATA using the user-written command 'mtefe' (Andresen, 2018).

${ }^{23}$ Equation (28) in Cornelissen et al. (2016) shows that we can calculate the ATT as follows: $A T T=$ $\frac{1}{N} \sum_{i=1}^{N} \frac{p_{i}}{\bar{p}} X_{i}\left(\beta_{1}-\beta_{0}\right)+\sum_{u=1}^{100} \frac{\operatorname{Pr}\left(p_{i}>u / 100\right)}{100 \bar{p}} E\left(U_{i 1}-U_{i 0} \mid U_{i D}=u / 100\right)$ with $p_{i}$ the predicted propensity score for $i$ and $E\left(U_{i 1}-U_{i 0} \mid U_{i D}=u / 100\right)$ the unobserved component of the MTE. We find that $\operatorname{Pr}\left(p_{i}>u / 100\right)$ is approximately 0 for all $u>81$.
} 
with $\gamma, \delta, \beta_{0}$ and $\beta_{1}$ parameters to estimate. The model is then completed by assuming a distribution of $U_{1 i}, U_{0 i}$ and $V_{i}$. We assume that the error terms are jointly normal with a mean-zero vector and correlation matrix $\Omega$ :

$$
\Omega=\left(\begin{array}{ccc}
1 & \rho_{0} & \rho_{1} \\
& 1 & \rho_{10} \\
& & 1
\end{array}\right) .
$$

Because $Y_{1 i}$ and $Y_{0 i}$ are never observed simultaneously, the joint distribution of $\left(U_{1 i}, U_{0 i}\right)$ and thus their correlation $\rho_{10}$ is not identified. We can however estimate correlations between $U_{0 i}$ and $V_{i}: \rho_{0}$ and between $U_{1 i}$ and $V_{i}: \rho_{1} \cdot{ }^{24}$ Since the joint distribution of each outcome equation and the selection equation is identified, we have sufficient information to calculate the ATE, ATT and ATNT for each value of $x$ (Lokshin and Sajaia, 2011). We then integrate over its empirical distribution to construct the overall averages. This model also allows us to identify average marginal effects by calculating how the treatment effects differ when one of the covariates changes value, keeping the other covariates constant.

\subsection{Factor model and distributional treatment effects}

While $\rho_{10}$ was not needed for average effects, it is necessary to know more about the distribution of treatment effects. In particular, we are interested in the proportion of students experiencing positive or negative treatment effects. Aakvik et al. (2005) show that identification can be achieved by imposing a factor structure on the error terms. ${ }^{25}$ Aakvik et al. (2005) follow a similar structure as in (3), but instead of directly estimating covariances between error terms, they impose the following structure:

$$
\begin{gathered}
V_{i}=-\theta_{i}+\varepsilon_{D i}, \\
U_{0 i}=-\alpha_{0} \theta_{i}+\varepsilon_{0 i}, \\
U_{1 i}=-\alpha_{1} \theta_{i}+\varepsilon_{1 i},
\end{gathered}
$$

with $\theta, \varepsilon_{D}, \varepsilon_{0}$ and $\varepsilon_{1}$ all independently distributed (e.g. $N(0,1)$ ); that is, correlation between error terms enters exclusively through one common factor, $\theta_{i}$. This imposes the

\footnotetext{
${ }^{24}$ We estimate the model in STATA using the user-written command 'switch_probit' (Lokshin and Sajaia, 2011).

${ }^{25}$ The non-identification of $\rho_{10}$ was also addressed by Poirier and Tobias (2003) without imposing a factor model. They make use of an algorithm in Koop and Poirier (1997), who use the restrictions that come from the positive definiteness of the covariance matrix of the error terms to learn about the value of $\rho_{10}$. The authors use a Bayesian procedure to estimate its distribution but warn that the results can depend on the prior that is chosen for $\rho_{10}$.
} 
restriction that correlation between unobservables of the potential outcomes of both school options are driven by the same underlying reason for choosing the school. $\theta_{i}$ can, for example, be interpreted as unobserved ability of the student or the social status of the family. If the strongest students select into treatment, we should see $\alpha_{0}>0$ and $\alpha_{1}>0$. With selection on gains, we would have $\alpha_{1}>\alpha_{0}$. However, if unobserved preferences for treatment are correlated with behavior that reduces the outcome, we can have $\alpha_{1}<\alpha_{0}$, with $\alpha_{1}$ possibly negative. An alternative interpretation of $\theta_{i}$ is that it captures the local quality of schools. If, for many students, the local elite and non-elite school are of similar quality but for some the elite school is better, we would expect $\alpha_{1}>\alpha_{0}$ if students in these neighborhoods are more likely to attend an elite school (i.e., having higher values of $\theta_{i}$ ). With normally distributed $\theta, \varepsilon_{D}, \varepsilon_{0}$ and $\varepsilon_{1}$, the model is identical to the one we proposed in the previous subsection with $\rho_{j}=\frac{\alpha_{j}}{\sqrt{2} \sqrt{1+\alpha_{j}^{2}}}$ for $j \in\{0,1\} .{ }^{26}$ The previously unidentified correlation, $\rho_{10}$, is now identified, as it only depends on the two factor loadings: $\rho_{10}=\frac{\alpha_{0} \alpha_{1}}{\sqrt{1+\alpha_{0}^{2}} \sqrt{1+\alpha_{1}^{2}}}=2 \rho_{0} \rho_{1}$. This identity can then be used to calculate distributional treatment effects. ${ }^{27}$ Note that this factor structure was only needed to identify $\rho_{10}$ and therefore has no impact on the estimates of the ATT, ATNT, ATE, or marginal effects.

To estimate this model, we proceed as follows: we first estimate (3) with error structure (4) using maximum likelihood to calculate the ATT, ATNT, ATE, and the average marginal effects of observed characteristics. We then apply the additional structure on the error terms (5) to calculate distributional treatment effects.

\section{Instrument validity}

We use the relative distance to an elite school as an instrument for school choice. We define the relative distance as the distance to the closest non-elite high school, subtracted by the distance to the closest elite high school. The use of geographical variation as an instrument for school choice has been proposed by Card (1995) and has also been used more recently in the educational literature (see, for example, Barrow et al. (2015), Carneiro et al. (2016) and Nybom (2017)). In this section, we provide a discussion of the assumptions of the instrument: relevance, independence and common support. Note also that a fourth

\footnotetext{
${ }^{26}$ Note that normalizations are different. Instead of (implicitly) normalizing the variances of $V_{i}, U_{0 i}$, and $U_{1 i}$ to be 1, the model of Aakvik et. al (2005) implies variances of respectively $2, \alpha_{0}^{2}+1$ and $\alpha_{1}^{2}+1$; that is, our estimates should be multiplied by the square roots of these numbers to translate them to their model.

${ }^{27}$ With the three correlation parameters identified, we can take draws from the estimated error distribution, calculate the potential outcomes and simulate treatment effects. We also directly estimate the factor model using the 'gsem' command in STATA and obtain identical results for the treatment effects.
} 
assumption, monotonicity, was implied by the selection model (2). This implies that all students must perceive distance as a cost and not as a benefit.

\subsection{Relevance}

The first assumption implies that distance should have a strong impact on school choice. Table 3 shows the results of the first stage of a 2SLS regression.

Table 3: First stage: choosing an elite school

\begin{tabular}{|c|c|c|c|c|}
\hline \multirow[b]{2}{*}{ Variables } & \multicolumn{2}{|c|}{ (1) } & \multicolumn{2}{|c|}{$(2)$} \\
\hline & Coef. & St. error & Coef. & St. error \\
\hline Relative distance & $0.024^{*}$ & $(0.001)$ & $0.024^{*}$ & $(0.001)$ \\
\hline Mother no high school degree ${ }^{a}$ & & & $-0.181^{*}$ & $(0.004)$ \\
\hline Mother high school degree ${ }^{a}$ & & & $-0.123^{*}$ & $(0.003)$ \\
\hline No Dutch at home & & & $0.063^{*}$ & $(0.007)$ \\
\hline Low income & & & $-0.029^{*}$ & $(0.003)$ \\
\hline Male & & & $-0.011^{*}$ & $(0.003)$ \\
\hline Repeated & & & $-0.121^{*}$ & $(0.004)$ \\
\hline Neighborhood characteristics & \multicolumn{2}{|c|}{ yes } & \multicolumn{2}{|c|}{ yes } \\
\hline Observations & \multicolumn{2}{|c|}{111,571} & \multicolumn{2}{|c|}{111,571} \\
\hline R-squared & \multicolumn{2}{|c|}{0.131} & \multicolumn{2}{|c|}{0.169} \\
\hline F-stat excl. instr. & \multicolumn{2}{|c|}{867} & \multicolumn{2}{|c|}{878} \\
\hline
\end{tabular}

Note: Standard errors are corrected for clustering within the statistical sector. Neighborhood characteristics include population density, median household income, the share of Belgians and average educational level at the municipality and the statistical sector. Both regressions additionally control for province fixed effects and indicators for the level of urbanization of the municipality.

* Statistical significance at $5 \%$ level.

${ }^{a}$ Base category $=$ mother has a degree in higher education.

The first specification only controls for the neighborhood characteristics summarized in Table 1, fixed effects for each of the five provinces and for each level of urbanization of the municipality. The second specification additionally controls for student characteristics. By controlling for neighborhood characteristics, we allow for the fact that parents' location preferences might not be independent from their children's performance. The relative distance has the expected positive sign and is highly significant, resulting in a high F-statistic of the exclusion restriction. Students (or their parents) are sensitive to distances to schools when 
making the choice to attend an elite high school as an additional kilometer to a non-elite high school (or an equal reduction in the distance to the elite school) makes them 2.4 percentage points more likely to choose the elite school. This estimate does not change when controlling for observed student characteristics (which is what we would expect from a valid instrument). The control variables do already indicate that selection into elite schools is non-random, as disadvantaged students are less likely to choose an elite school. The only exception is students who do not speak Dutch at home, as they are more likely to choose an elite school but they also have lower expected outcomes. ${ }^{28}$

\subsection{Independence}

The second condition (independence) implies that differences in distances must be independent from unobservables in the outcome equation. First, we argue, based on institutional grounds, that distance to schools is an exogenous instrument for school choice in Flanders. Second, we show that in our main specification, distances are not correlated with observed student characteristics.

While distances can be problematic in a number of institutional contexts, we argue that this is not the case in Flanders. ${ }^{29}$ Unrestricted school choice is protected by the Belgian constitution (art. 24, §1) and most students live close to several schools. They can choose between 667 schools in Flanders of which 131 are elite schools. For the median student, six schools are located within a $5 \mathrm{~km}$ distance. ${ }^{30}$ Students can also benefit from inexpensive public transportation or cycle lanes, the most common means of transportation for high school students. Parents are still expected to take neighborhood characteristics into account when moving. These characteristics might be correlated with the presence of an elite school. Controlling for neighborhood characteristics addresses this concern.

For distance to be a valid instrument, it should be independent from unobserved student characteristics. Although we cannot exclude that travel distance could still be correlated with unobserved student characteristics, it would be reassuring if it is not correlated with observed student characteristics. In Table 4, we show the results of an OLS regression of rela-

\footnotetext{
${ }^{28} \mathrm{~A}$ possible explanation is that this variable groups students from very diverse migrant backgrounds, both low and high skilled, and is therefore difficult to interpret. While low skilled migration was very common in Flanders for industrial production during the 20th century, high skilled migration is also important because of Flanders' proximity to Brussels, the capital of the European Union.

${ }^{29}$ Altonji et al. (2005) show that distance is not a valid instrument by which to identify the effect of attending a Catholic high school using data from the US.

${ }^{30}$ In Supporting Information Appendix B, we show that our main results are similar when we restrict the sample to students who have at least four schooling options in a $5 \mathrm{~km}$ radius and who have an elite school among the four closest options.
} 
tive distance on student characteristics. After conditioning on neighborhood characteristics, student characteristics are not correlated with relative distance. A joint significance test is strongly rejected, and each covariate is precisely estimated around 0 . The largest impact we find is for parental education: students with a mother without a high school degree live 55 $\mathrm{m}$ further from an elite school than students with a mother with a higher education degree. This is a very short distance, precisely estimated, but still only significantly different from 0 at the $10 \%$ level. We conclude that after controlling for neighborhood characteristics, we do not find evidence of selection into neighborhoods with elite schools based on observed student characteristics. $^{31}$

Table 4: Regression of relative distance on student characteristics

\begin{tabular}{lcc}
\hline Variables & Coef. & St. error \\
\hline Mother no high school degree $^{a}$ & -0.055 & $(0.033)$ \\
Mother high school degree $^{a}$ & -0.023 & $(0.024)$ \\
No Dutch at home & 0.040 & $(0.062)$ \\
Low income & -0.046 & $(0.030)$ \\
Male & -0.010 & $(0.019)$ \\
Repeated & -0.025 & $(0.032)$ \\
Neighborhood characteristics & \multicolumn{2}{c}{ yes } \\
F-test individual characteristics & \multicolumn{2}{c}{$1.28(\mathrm{p}=0.263)$} \\
Observations & \multicolumn{2}{c}{111,571} \\
\hline
\end{tabular}

Note: Standard errors are corrected for clustering within the statistical sector.

Neighborhood characteristics include population density, median household income, the share of Belgians and average educational level at the municipality and the statistical sector. The regression additionally controls for province fixed effects and indicators for the level of urbanization of the municipality.

* Statistical significance at $5 \%$ level.

${ }^{a}$ Base category $=$ mother has a degree in higher education.

\footnotetext{
${ }^{31}$ Supporting Information Appendix C shows that it is particularly important to control for intraregional differences, captured by dummy variables for the provinces and the levels of urbanization. When we do not control for neighborhood characteristics, the effect of student characteristics on travel distance is larger and significant. This is because we find that academic outcomes are lower in urban areas. At the same time, distances to different types of schools are smaller in urban areas, which implies that elite schools are more accessible for students living in cities. Not controlling for neighborhood characteristics then leads to a downward bias in the estimates of the treatment effects.
} 


\subsection{Common support}

This last condition implies that for each value of the propensity score $P(x, z)$, there should be treated and non-treated individuals. This condition is needed only for the semi-parametric approach. We estimate the propensity score using a probit regression and plot the histogram of common support in Figure 1.

Figure 1: Common support

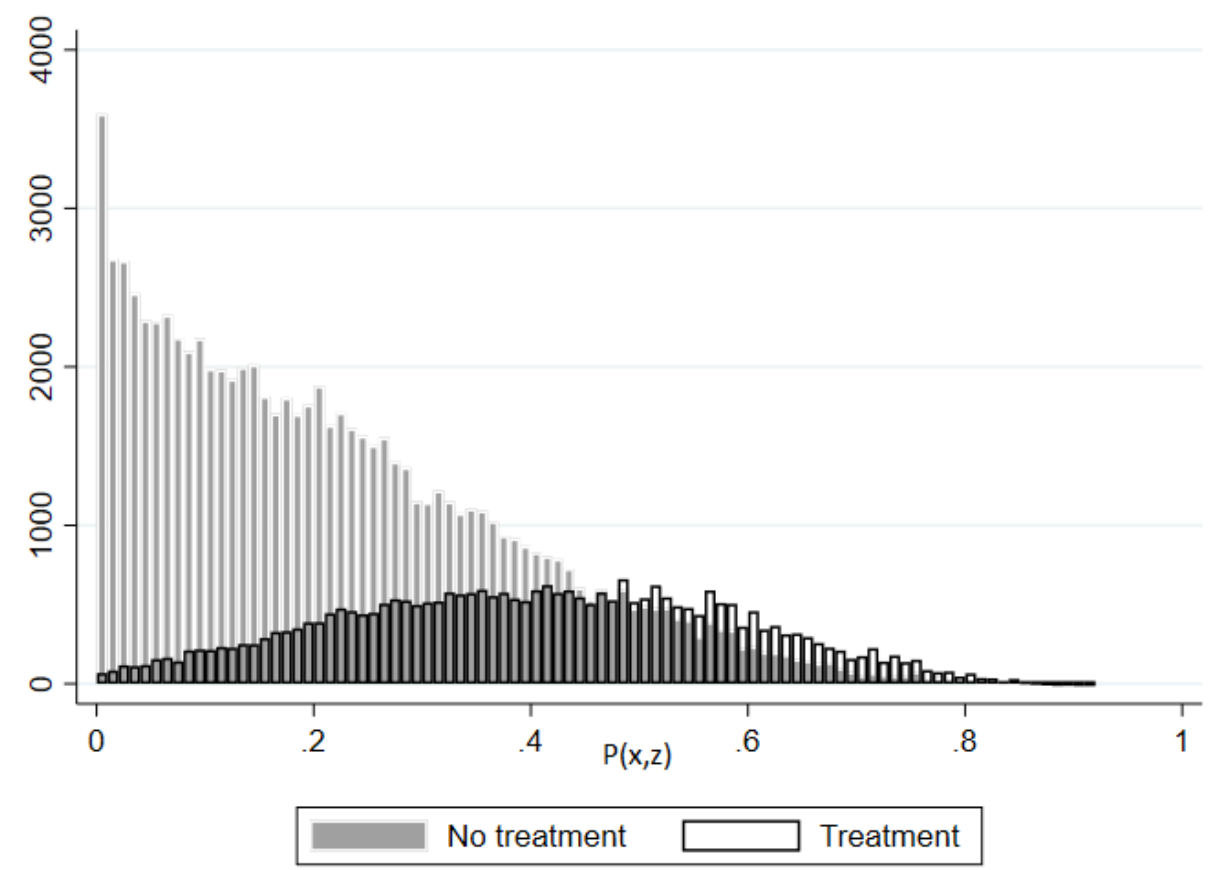

Note: This figure plots the number of treated and non-treated students for each percentile of the propensity score (111,571 students).

The common support assumption is satisfied for values of $P(x, z)$ up until 0.81. For higher values of $P(x, z)$, there are almost no treated or non-treated students and the MTE cannot be identified. ${ }^{32}$ This allows us to compute the ATT because the weights in the calculation of the ATT become 0 for $u_{D}>0.81 .{ }^{33}$ Therefore, we do not need estimates of the MTE for $u_{D}>0.81$ and thus we do not need common support at $P(x, z)>0.81$. We plot the weights in Figure D1 in Supporting Information Appendix D. The ATT attaches more weight to students with low costs of treatment (low $u_{D}$ ) as they are more likely to select into treatment.

\footnotetext{
${ }^{32}$ Each percentile up until 0.81 contains at least 10 treated and 10 non-treated students. For most percentiles above 0.81 , this condition is not satisfied so we do not report an MTE here.

${ }^{33}$ In practice, the weights are non-zero but very small (see Figure D1).
} 


\section{$5 \quad$ Empirical results}

Before discussing the heterogeneity of the treatment effect, we briefly discuss the results of OLS and 2SLS regressions that ignore heterogeneity in the treatment effect (see Supporting Information Appendix D, Table D1). OLS finds a positive effect from treatment, (i.e., students would, on average, be more likely to graduate from high school if they choose an elite school), but this effect decreases when controlling for background characteristics. When we control for self-selection with a 2SLS regression, but ignore heterogeneous treatment effects, the 2SLS estimate turns out to be statistically insignificant.

\subsection{Estimation results}

We estimate both a semi-parametric and parametric model, as explained in Section 3. For the semi-parametric model, we show the estimation results of the observable part of the treatment effect in Table D2 in Supporting Information Appendix D. In Figure 2, we plot the unobservable part; that is, the MTE curve. ${ }^{34}$ On the horizontal axis, we present $u_{D}$. Students with a low $u_{D}$ have a low unobserved cost (or a high unobserved preference) for elite schools and are therefore more likely to be treated. Figure 2 shows that the treatment effect remains constant and almost never significantly differs from zero. This does not mean that treatment effects are constant. Many of the control variables are capturing heterogeneity in returns. As expected from the MTE curve, we cannot reject the hypothesis of no unobserved heterogeneity in the treatment effect $(\mathrm{p}$-value $=0.424)$ but we strongly reject this on observables ( $\mathrm{p}$-value $=0.000)$.

Table D3 in Supporting Information Appendix D contains the estimates of the parametric model. Here we find a statistically significant impact of unobservables. The unobservable in the non-treated outcome is positively correlated with the unobservable in the selection equation $\left(\rho_{0}=0.193\right)$. This is consistent with the idea that stronger students select into elite schools. However, for the treated outcome we find a negative correlation $\left(\rho_{1}=-0.185\right) .{ }^{35}$ This suggests that these stronger students lose their advantage by attending an elite school. Note that the unobserved factor captures only what observable characteristics fail to explain in the correlation between preferences for elite schools and high school graduation. A potential explanation for the different sign of $\rho_{0}$ and $\rho_{1}$ is that an important number of students with a high preference for elite schools is at risk of not being able to pursue the academic

\footnotetext{
${ }^{34}$ The bandwidths of the local polynomial regressions are determined by the asymptotically optimal constant bandwidth (Fan and Gijbels, 1996).

${ }^{35}$ As explained in section 3.4, we can also use these correlations to identify the factor loadings in the model of Aakvik et al. (2005): $\alpha_{0}=0.283$ and $\alpha_{1}=-0.271$.
} 
Figure 2: Obtaining a high school degree: MTE

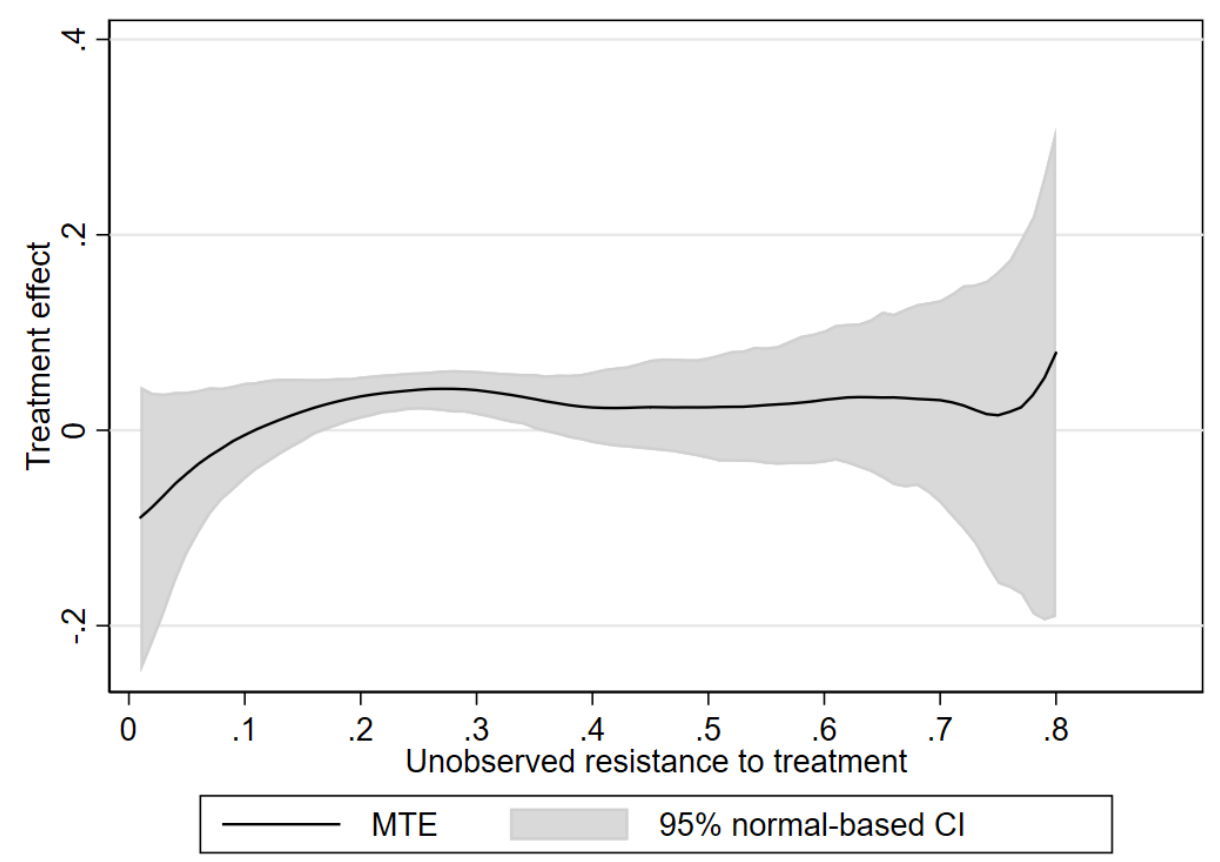

Note: MTEs are calculated based on 111,571 students using a local polynomial regression of degree 2 with an Epanechnikov kernel. Standard errors are computed with a bootstrap procedure (250 replications) and clustered within the statistical sector. P-value no observable heterogeneity (0.000), p-value no unobservable heterogeneity (0.424).

track. They could have above average ability, leading to better outcomes in non-elite schools. At the same time, they are not top performers implying that they have a risk of failing in the academic track. This can have detrimental effects on the probability to graduate from high school if their high preference makes them unwilling to switch to another school. In section 6 we investigate the interaction between school and track choice and find further evidence for this explanation. ${ }^{36}$

\subsection{Average and distributional treatment effects}

\section{ATT, ATNT and ATE}

\footnotetext{
${ }^{36}$ Reverse selection on unobserved gains is not uncommon in the literature as it has also been established in Aakvik et al. (2005) on the effects of a rehabilitation program on employment and Cornelissen et al. (2018) on the effects of universal child care on school outcomes.
} 
Table 5 compares the estimates of the average treatment effects of the semi-parametric and parametric model. In order to be able to compute these three different treatment effects with the semi-parametric approach, the common support assumption should be satisfied. In general, this assumption is difficult to satisfy, but we are able to identify a statistically insignificant ATT of 0.4 percentage points. This implies that, on average, students in elite schools do not experience an effect on the probability of graduating from high school.

Table 5: Obtaining a high school degree: average treatment effects

\begin{tabular}{|c|c|c|c|c|}
\hline & \multicolumn{2}{|c|}{ Semi-parametric approach } & \multicolumn{2}{|c|}{ Parametric approach } \\
\hline & Coef. & St. error & Coef. & St. error \\
\hline ATT & 0.004 & $(0.019)$ & -0.016 & $(0.008)$ \\
\hline ATNT & \multicolumn{2}{|c|}{ Not identified ${ }^{a}$} & $0.051^{*}$ & $(0.010)$ \\
\hline ATE & \multicolumn{2}{|c|}{ Not identified ${ }^{a}$} & $0.033^{*}$ & $(0.008)$ \\
\hline
\end{tabular}

Note: Average treatment effects are calculated based on 111,571 students. Standard errors are corrected for clustering within the statistical sector and computed with a bootstrap procedure using 250 replications.

* Statistical significance at $5 \%$ level.

${ }^{a}$ Not identified due to insufficient common support.

As explained in Section 3.3, we also impose a parametric structure. Despite the extra structure, we still obtain a statistically insignificant ATT (-1.6 percentage points). The parametric model also allows us to compute the ATE and ATNT. We derive a significantly positive ATE of 3.3 percentage points and a larger ATNT of 5.1 percentage points. These results imply that students who do not attend elite schools would, on average, be 5.1 percentage points more likely to graduate from high school when they would have chosen an elite school, while students who attend elite schools do not, on average, experience an effect from treatment. ${ }^{37}$

\section{Average marginal effects of student characteristics}

The average treatment effects can still mask a lot of heterogeneity within both groups of treated and non-treated students. To investigate this further, we consider the effect of ob-

\footnotetext{
${ }^{37}$ We repeated the analysis with an alternative outcome variable: obtaining a high school degree without study delay (i.e., within six years of studying). Other studies have found that grade retention has a negative effect on performance in the final years of high school (Cockx et al., 2018) and on the student's beginning-ofcareer wage (Brodaty et al., 2013). Similar to our main outcome, we obtain a statistically insignificant ATT but we find even stronger positive effects for the ATNT. The results can be found in Supporting Information Appendix D Tables D4, D5 and D6, and the MTE in Figure D2.
} 
servable characteristics and calculate distributional treatment effects. We report the average marginal effects of each background variable in Table 6, as computed from the parametric model. They report the change in the ATE when the value of the control variable changes from 0 to 1 for all individuals in the sample. As these effects differ between individuals, we evaluate them for each student in the sample at their actual realizations of all other variables and report the mean effect.

Table 6: Obtaining a high school degree: average marginal effects and distributional effects

\begin{tabular}{lcc}
\hline & Coef. & St. error \\
\hline Average marginal effects of student background & & \\
Mother has no high school degree $^{a}$ & $0.049^{*}$ & $(0.010)$ \\
Mother has high school degree $^{a}$ & $0.014^{*}$ & $(0.005)$ \\
No Dutch at home & -0.011 & $(0.008)$ \\
Low income & -0.005 & $(0.004)$ \\
Male & 0.010 & $(0.006)$ \\
Repeated & $0.028^{*}$ & $(0.012)$ \\
& & \\
Distributional treatment effects & \\
Among all students & & \\
$\%$ benefit from elite school & & $(0.239)$ \\
$\%$ suffer from elite school & $7.232^{*}$ & $(0.616)$ \\
Among students in elite school & $3.941^{*}$ & \\
$\%$ benefit from elite school & & $(0.702)$ \\
$\%$ suffer from elite school & $3.680^{*}$ & $(0.176)$ \\
Among student in non-elite school & $5.220^{*}$ & \\
$\%$ benefit from elite school & & $(0.233)$ \\
$\%$ suffer from elite school & $8.549^{*}$ & $(0.837)$ \\
\hline
\end{tabular}

Note: Average marginal effects and distributional treatment effects are calculated based on 111,571 students. Standard errors are corrected for clustering within the statistical sector and computed with a bootstrap procedure using 250 replications. Average marginal effects of control variables report the change in the ATE when the value of the control variable would change from 0 to 1 . Distributional effects calculated by simulating the error terms of the potential outcome framework (100 draws for each student).

* Statistical significance at $5 \%$ level.

${ }^{a}$ Base category $=$ mother has a degree in higher education.

${ }^{b}$ Requires identification of $\rho_{10}$ using factor structure Aakvik et al. (2005). 
The average marginal effects are suggestive of reverse selection on gains. Table 6 shows that choosing an elite school has larger positive effects for students whose mother did not complete high school and students who repeated at least one grade in primary school. However, these students are less likely to choose an elite school (see Table D3 in Supporting Information Appendix D for estimates of the selection equation). As explained before, the estimates also reveal such a pattern for unobservables. An example that is consistent with this story is that of a low ability student from a high social class who is strongly encouraged by his parents to attend an elite school but would be more likely to graduate from high school when choosing a non-elite school. The reverse is also possible. High ability students with a low social status might not choose an elite school, even if they would be more successful in this type of school. As we find the strongest marginal effects for the educational level of the mother (a proxy for social status), we believe this is a plausible story.

\section{Distributional treatment effects}

The extra structure imposed by the factor model of Aakvik et al. (2005) is necessary (only) to compute distributional treatment effects. Distributional treatment effects are another measure of the heterogeneity of the treatment effect and identify the fraction of students who experience or would have experienced (in case of no treatment) a positive or negative treatment effect. The second panel of Table 6 shows the distributional treatment effects for the total population of students, the group of students who started at elite schools and the group of students who started at non-elite schools. In total, $7.2 \%$ of students experience a positive treatment effect. Note that the treatment effect is large, as it involves a switch from not obtaining a degree to obtaining a degree (or vice versa); that is, $7.2 \%$ of students would obtain a degree at an elite school but not at a non-elite school. A smaller fraction of $3.9 \%$ would graduate from high school only if they started at a non-elite school. Among the group of treated students, we compute that $5.2 \%$ of students experience a negative treatment effect and that only $3.7 \%$ experience gains from attending an elite school. This is consistent with our previous findings that show that students in non-elite schools would experience the most positive treatment effects. Among the group of students in non-elite schools, $8.5 \%$ would experience a positive treatment effect, while only $3.5 \%$ would lose from attending an elite school. According to this outcome, we can conclude that $7.6 \%$ of students would have been better off in the other school type. ${ }^{38}$

The fact that students can be negatively affected by an elite school is not new. PopEleches and Urquiola (2013) find that parents reduce their effort when their child enters an

\footnotetext{
${ }^{38}$ This is the result of a weighted sum: $5.2 \%$ of the $26.7 \%$ in elite schools suffer, while $8.5 \%$ of the $73.3 \%$ in non-elite schools would gain.
} 
elite school. They also find that relatively weak students in better-ranked schools feel more marginalized and insecure than similar students in other schools. A negative effect can also be explained by differences in grading standards and demands from students. Schools have some autonomy in deciding about grade progression and excluding students from certain programs. It is therefore possible that elite schools more often require weaker students to repeat a grade in order to achieve the required schooling level, which could demotivate students and therefore result in drop out.

Another potential explanation for the heterogeneity in the effects is that elite schools differ from non-elite schools in their supply of tracks. If students are not aware of their ability from the start of high school, a wrong track choice may occur. This could be problematic when they are in an elite school as it makes it more difficult to switch to a lower ranked track. We will explore this channel further in Section 6.

\section{Explaining heterogeneity in the treatment effect by track choices}

In this section, we explain our two main findings. First, attending an elite school, on average, increases degree completion, but only for the non-treated students. This implies that there is a reverse selection on gains. Second, there is substantial heterogeneity within each school type, which implies that a substantial fraction of students in both elite and non-elite schools experience a positive or negative treatment effect from attending an elite school.

We explain these results by extending the factor model of Section 3.4 with the track choice that students make in the second year of high school (grade 8). ${ }^{39}$ We then use this model to isolate the effect of the tracking decision by simulating the track choice that students would make in each type of school. First, we find that choosing an elite school raises the likelihood of enrolling in the academic track. Second, elite schools make students more likely to persist and succeed in this track. Third, this is the case only for non-treated students as treated students tend to enroll in the academic track, independent of the type of school they choose in the first year. This can explain why the ATNT is more positive than the ATT. Finally, we find that treated students are negatively affected by an elite school if they are not able to pursue the academic track. Their preference for elite schools makes them unwilling to switch to another school in order to choose a lower ranked track, which could help them

\footnotetext{
${ }^{39}$ As explained in Section 2, the "official" track distinction starts a year later (grade 9) but study programs in grade 8 are already aligned with the track. We therefore also show the results using the track in grade 9 instead and find similar effects (see Supporting Information Appendix D, Table D9 and Table D10).
} 
avoid study delay and dropout. In the last part of this section, we provide further evidence for this by repeating our main analysis on the probability to downgrade.

\subsection{Endogenous tracking decisions}

Entering the academic track is given by an indicator $A_{j i}=1\left(\sigma_{j} Z_{i}^{\text {track }}+\kappa_{j} X_{i}-U_{j i}^{\text {track }} \geq 0\right)$, with $j=0$ when $i$ entered a non-elite school and $j=1$ if $i$ entered an elite school. Track choices therefore depend on the same set of covariates $X_{i}$ that affect the choice of the type of school, but also the relative distance to the nearest school that offers the academic track $Z_{i}^{\text {track }}{ }^{40}$ We further extend the model to have four instead of two potential outcomes (conditional on each school type and track). ${ }^{41}$ The error terms are still generated by a factor model. The impact of the unobserved factor $\theta_{i}$ on all error terms is estimated through factor loadings and the remaining variation is captured by independent shocks that are normally distributed.

The estimates can be found in Supporting Information Appendix D, Tables D7 and D8. Table 7 shows the estimated treatment effects of the model. First, we show the treatment effects of choosing an elite school on degree completion in secondary education according to this model. As expected, endogenizing the track decisions does not have an important impact on the overall effect of attending an elite school, as we found in Table 5. Next, we find that choosing the academic track raises the probability of graduating from high school for the treated $(+6.8$ percentage points) and the non-treated $(+4.5$ percentage points). In contrast to the treatment effects of elite schools, we do not see reverse selection on gains for this treatment. Nevertheless, non-treated students would, on average, also gain from enrolling in the academic track. Finally, we show that choosing an elite school makes students, on average, 23.1 percentage points more likely to enroll in the academic track. This average effect is largely driven by non-treated students whose impact is more than three times larger than the impact for treated students. This can be explained by the correlation between preferences for elite schools and preferences for the academic track. ${ }^{42}$ Many treated students

\footnotetext{
${ }^{40}$ We define $Z_{i}^{\text {track }}$ as the distance to the closest school that offers a non-academic track, subtracted by the distance to the closest school that offers an academic track.

${ }^{41} \mathrm{We}$ also add $Z_{i}^{\text {track }}$ as a covariate in the school choice equation to allow students to consider the distance to the academic track when making their schooling decision. Note that the large number of neighborhood characteristics we control for requires us to constrain some of their effects. We assume that the parameters of neighborhood characteristics in the track choice equations do not depend on the initial school choice. As in the baseline model, we allow their effects on the outcome to differ between both school choices, but we restrict them to be the same over track choices. Note that we still allow individual characteristics (observed and unobserved) to enter in a fully flexible way.

${ }^{42}$ Table D7 shows that observable characteristics predicting students to enroll in the elite school are the
} 
would enroll in the academic track in any case, while this is not true for the non-treated students who are more encouraged to enroll in the academic track if they attended an elite school.

Table 7: Extended model: average treatment effects

\begin{tabular}{lcccccc}
\hline & Coef. & St. error & Coef. & St. error & Coef. & St. error \\
\hline $\begin{array}{l}\text { Treatment } \\
\text { Outcome }\end{array}$ & \multicolumn{2}{c}{ Elite school } & \multicolumn{2}{c}{ Academic track } & Elite school \\
& \multicolumn{2}{c}{$\begin{array}{c}\text { High school degree } \\
\text { Academic track }\end{array}$} \\
ATT & -0.008 & $(0.007)$ & $0.068^{*}$ & $(0.014)$ & $0.076^{*}$ & $(0.008)$ \\
ATNT & $0.049^{*}$ & $(0.011)$ & $0.045^{*}$ & $(0.013)$ & $0.287^{*}$ & $(0.036)$ \\
ATE & $0.033^{*}$ & $(0.008)$ & $0.061^{*}$ & $(0.012)$ & $0.231^{*}$ & $(0.028)$ \\
\hline
\end{tabular}

Note: Average treatment effects are calculated based on 111,571 students. Standard errors are corrected for clustering within the statistical sector and computed by sampling 250 draws from the estimated distribution. For each draw of the estimates we calculate the treatment effects by simulating the error terms of the potential outcome framework (100 draws for each student).

* Statistical significance at $5 \%$ level.

In our model, we allow for two channels through which elite schools can affect degree completion. First, elite schools can have a direct effect on degree completion. This could be related to better peers or teachers, for example. Second, elite schools encourage students to start at the academic track and thereby make them more likely to obtain a degree. In Table 8 , we isolate the direct effect of choosing an elite school by simulating degree completion for treated and non-treated students, while keeping the track choice fixed.

same as those predicting them to enroll in the academic track. This pattern also holds for unobservables. We find a factor loading of 0.870 for students in non-elite schools and 0.251 for students in elite schools. As the factor loading of attending an elite school is normalized to 1, a positive load on the track choice points to a positive correlation in unobserved preferences for elite schools and the academic track. 
Table 8: Extended model: average treatment effects conditional upon track choice

\begin{tabular}{lcccccc}
\hline & \multicolumn{2}{c}{ No restrictions } & \multicolumn{2}{c}{ Only academic track } & \multicolumn{2}{c}{ No academic track } \\
& Coef. & St. error & Coef. & St. error & Coef. & St. error \\
\hline ATT & -0.008 & $(0.007)$ & -0.003 & $(0.006)$ & $-0.130^{*}$ & $(0.036)$ \\
ATNT & $0.049^{*}$ & $(0.011)$ & $0.042^{*}$ & $(0.012)$ & 0.000 & $(0.025)$ \\
ATE & $0.033^{*}$ & $(0.008)$ & $0.030^{*}$ & $(0.009)$ & -0.035 & $(0.024)$ \\
\hline
\end{tabular}

Note: Average treatment effects are calculated based on 111,571 students. Standard errors are corrected for clustering within the statistical sector and computed by sampling 250 draws from the estimated distribution. For each draw of the estimates we calculate the treatment effects by simulating the error terms of the potential outcome framework (100 draws for each student).

* Statistical significance at $5 \%$ level.

The results in the first column are again the estimated treatment effects of choosing an elite school on high school graduation by our model when the track choice is not restricted. The next two columns show the treatment effects of choosing an elite school conditional upon track choice in the second year of high school. In the second specification, we simulate how treatment effects would change if every student would enroll in the academic track. While the ATT is identical to the baseline case, the ATNT is slightly smaller. ${ }^{43}$ In this simulation, elite schools no longer incentivize students to enroll in the academic track because all students now enroll in this track. The positive treatment effect for the non-treated suggests that elite schools not only raise the probability to choose the academic track but also success in the academic track.

Finally, we simulate how treatment effects would change when the academic track cannot be chosen by students. Note that in this case, students enrolled in elite schools have to move to another school after the first year, as only the academic track is offered at their initially chosen school. While the non-treated experience no effect, we find a large and negative ATT of -13.0 percentage points. This result shows that students with a high preference for elite schools (the treated) suffer when they are not able to start at the academic track and have to switch to a different school. For non-treated students this is less of an issue. They would also need to switch schools but rather it would be a switch to their preferred school in any case so it is not considered to be as costly.

\footnotetext{
${ }^{43}$ We also find a smaller ATNT when repeating our main analysis on the sample of students who choose the academic track in the second grade of high school (see Supporting Information Appendix B).
} 


\subsection{Downgrading}

The model in the previous subsection shows the large impact of elite schools on the initial track decision, as well as how treated and non-treated students react differently to the non-availability of a track. In this section, we show that this initial response also persists in the higher grades, by repeating our main analysis for an alternative outcome variable: downgrading.

The estimates can be found in the Supporting Information Appendix D, Tables D11 and D12 and the MTE in Figure D3. From the estimated treatment effects in Table 9, we can conclude that students with a high preference for elite schools are more prepared to stay in the academic track if they attend an elite school. Students with lower preferences experience no effect because they are more willing to change schools in order to switch tracks. This can also be seen in the average marginal effects (see Table 10). For most variables, such as low education of the mother and having repeated a grade in elementary school, we see that students benefitting more from elite schools (see Table 6) are also the ones who have positive marginal effects on the downgrading decisions. This implies that the negative ATE on downgrading of -4.1 percentage points is mostly coming from students who do not improve their chances of obtaining a high school degree, while students who do experience improvements do not let their downgrading decision depend on it. In an elite school, they make use of the opportunity to be more successful after choosing the academic track (see previous subsection), but if they need to switch at a later date, they are still willing to do so. Note that this high preference does not necessarily need to apply to the student. They can also be strongly encouraged by their parents to attend and/or stay in an elite school, even when teachers give the opposite advice.

Table 9: Downgrading: average treatment effects

\begin{tabular}{lcccc}
\hline & \multicolumn{2}{c}{ Semi-parametric approach } & \multicolumn{2}{c}{ Parametric approach } \\
& Coef. & St. error & Coef. & St. error \\
\hline ATT & $-0.133^{*}$ & $(0.021)$ & $-0.109^{*}$ & $(0.020)$ \\
ATNT & \multicolumn{2}{c}{ Not identified $^{a}$} & -0.016 & $(0.024)$ \\
ATE & \multicolumn{2}{c}{ Not identified $^{a}$} & $-0.041^{*}$ & $(0.019)$ \\
\hline
\end{tabular}

Note: Average treatment effects are calculated based on 111,571 students. Standard errors are corrected for clustering within the statistical sector and computed with a bootstrap procedure using 250 replications.

* Statistical significance at $5 \%$ level.

${ }^{a}$ Not identified due to insufficient common support. 
These results suggest that it is important to reorient students to another track if they perform less well during secondary education in order to avoid high school drop-out. This finding is consistent with Dustmann et al. (2017), who find that the possibility to change tracks over time is important in order to mitigate possible negative long-term effects of early tracking.

Table 10: Downgrading: average marginal effects

\begin{tabular}{lcc}
\hline & Coef. & St. error \\
\hline Mother has no high school degree $^{a}$ & $0.074^{*}$ & $(0.016)$ \\
Mother has high school degree $^{a}$ & $0.047^{*}$ & $(0.011)$ \\
No Dutch at home & $-0.049^{*}$ & $(0.015)$ \\
Low income & $0.019^{*}$ & $(0.009)$ \\
Male & $0.062^{*}$ & $(0.007)$ \\
Repeated & $0.128^{*}$ & $(0.014)$ \\
\hline
\end{tabular}

Note: Average marginal effects are calculated based on 111,571 students. Standard errors are corrected for clustering within the statistical sector and computed with a bootstrap procedure using 250 replications. Average marginal effects of control variables report the change in the ATE when the value of the control variable would change from 0 to 1 .

* Statistical significance at $5 \%$ level.

${ }^{a}$ Base category $=$ mother has a degree in higher education.

\section{Conclusion}

We study the causal and heterogeneous impact of choosing an elite high school on high school completion. Instead of offering study programs in different tracks, elite schools only offer programs in the academic track. We apply our analysis to an early tracking system in the region of Flanders in Belgium.

We find that there is substantial heterogeneity in the treatment effect, both within and between treatment groups. On average, students are 3.3 percentage points more likely to obtain a high school degree if they start at an elite school. However, students attending elite schools experience, on average, no effect of treatment, while students who do not choose an elite school would experience, on average, a significantly positive effect of 5.1 percentage points. We also find that treatment effects are greater for students from disadvantaged backgrounds who are less likely to choose an elite school. These findings imply that students with the lowest preference for elite schools experience the greatest positive effects. 
Further analysis shows that this heterogeneity can be explained by tracking decisions. Elite schools incentivize non-treated students to enroll and perform well in the academic track, which increases their chances of obtaining a degree. Treated students are already more likely to choose the academic track in both types of schools but instead have a higher risk of being mismatched because their high preference for the elite school interferes with their tracking decisions.

These results have important implications for educational policies for the region of Flanders and for other countries that apply some form of tracking. First, the average positive effects of elite schools imply that more students and especially students from disadvantaged backgrounds, should be encouraged to enroll in schools that offer only an academic track. More information about the capabilities of students to pursue an academic track could assist those students from disadvantaged backgrounds in particular to opt more often for academic high schools.

Second, the large heterogeneity in gains from elite and non-elite schools suggests that students may benefit considerably from school variety. Countries should not follow a one size fits all approach because allowing for different types of schools could improve degree completion. Students should have the choice between different schooling options within commuting distance. Countries that split students into different tracks through track-specific schools would benefit from also offering schools that offer multiple tracks.

Third, the reverse selection on gains shows that students are not optimally choosing their school. Thus, improved guidance or tests at the end of primary education may be useful. Furthermore, students with a high preference for academic schools but who are not able to pursue an academic track should be better guided towards other schools in order to prevent them from dropping out. Countries that organize their secondary education in track-specific schools could create clusters of different types of schools to smoothen the transition to other tracks if students do not perform well in the academic track.

Our analysis is limited to outcomes in secondary education. Graduating from elite schools could have benefits in higher education or on the labor market. Further research is needed in order to consider the effects of elite schools on other outcomes, such as success in higher education or on the labor market. 


\section{References}

Aakvik, A., Heckman, J. and Vytlacil, E. (2005), Estimating Treatment Effects for Discrete Outcomes when Responses to Treatment Vary: An Application to Norwegian Vocational Rehabilitation Programs, Journal of Econometrics 125 (1-2), 15-51

Abdulkadiroğlu, A., Angrist, J. and Pathak, P. (2014), The Elite Illusion: Achievement Effects at Boston and New York Exam Schools, Econometrica, 82 (1), 137-196

Altonji, J., Elder, T. and Taber, C. (2005), An Evaluation of Instrumental Variable Strategies for Estimating the Effects of Catholic Schooling, The Journal of Human Resources, 40 (4), 791-821

Andresen, M. (2018), Exploring marginal treatment effects: Flexible estimation using Stata, The Stata Journal, 18 (1), 118-158

Barrow, L., Whitmore Schanzenbach, D. and Claessens, A. (2015), The Impact of Chicago's Small High School Initiative, Journal of Urban Economics, 87, 100-113

Basu, A., Heckman, J., Navarro-Lozano, S. and Urzua, S. (2007), Use of Instrumental Variables in the Presence of Heterogeneity and Self-selection: An Application to Treatment of Breast Cancer Patients, Health Economics, 16, 1133-1157

Brodaty, T., Gary-Bobo, R. and Prieto, A. (2013), Does Speed Signal Ability? The Impact of Grade Retention on Wages, Working paper

Card, D. (1995), Using Geographic Variation in College Proximity to Estimate the Return to Schooling, Aspects of Labour Economics: Essays in Honour of John Vanderkamp, University of Toronto Press

Carneiro, P., Heckman, J., Vytlacil E. (2011), Estimating Marginal Returns to Education. American Economic Review, 101 (6), 2754-2781

Carneiro, P., Lokshin, M. and Umapathi, N. (2016), Average and Marginal Returns to Upper Secondary Schooling in Indonesia: Average and Marginal Returns to Schooling in Indonesia. Journal of Applied Econometrics, 32 (1), 16-36

Chmielewski, A. (2014), An International Comparison of Achievement Inequality in Withinand Between-school Tracking Systems, American Journal of Education 120 (3), 293-324 
Clark, D. and Del Bono, E. (2016), The Long-run Effects of Attending an Elite School: Evidence from the UK, American Economic Journal: Applied Economics, 8 (1), 150-176

Cockx, B., Picchio, M. and Baert, S. (2018), Modeling the Effects of Grade Retention in High School, Journal of Applied Econometrics, 34 (3), 403-424

Cornelissen, T., Dustmann, C., Raute, A. and Schönberg, U. (2016), From LATE to MTE: Alternative Methods for the Evaluation of Policy Interventions, Labour Economics, 41, 47-60

Cornelissen, T., Dustmann, C., Raute, A. and Schönberg, U. (2018), Who Benefits from Universal Child Care? Estimating Marginal Returns to Early Child Care Attendance, Journal of Political Economy, 126 (6), 2356-2409

Cummins, J. R. (2017), Heterogeneous treatment effects in the low track: Revisiting the Kenyan primary school experiment, Economics of Education Review, 56, 40-51

De Groote, O. (2019), A Dynamic Model of Effort Choice in High School, TSE working paper - 1002

Declercq, K. and Verboven, F. (2015), Socio-economic Status and Enrollment in Higher Education: Do Costs Matter?, Education Economics, 23 (5), 532-556

Doyle, J. (2007), Child Protection and Child Outcomes: Measuring the Effects of Foster Care, American Economic Review, 97 (5), 1583-1610

Doyle, J. (2008), Child Protection and Adult Crime: Using Investigator Assignment to Estimate Causal Effects of Foster Care, Journal of Political Economy, 116 (4), 746-770

Duflo, E., Dupas, P. and Kremer, M. (2011), Peer Effects, Teacher Incentives, and the Impact of Tracking: Evidence from a Randomized Evaluation in Kenya, American Economic Review, 101, 1739-1774

Dustmann, C., Puhani, P. and Schönberg, U. (2017), The Long-term Effects of Early Track Choice, Economic Journal, 127 (603), 1348-1380

Fan, J., and Gijbels, I. (1996), Local Polynomial Modelling and Its Applications, London: Chapman \& Hall.

Fu, C. and Mehta, N. (2018), Ability Tracking, School and Parental Effort, and Student Achievement: A Structural Model and Estimation, Journal of Labor Economics, 36 (4), 923979 
Galasso, A. and Schankerman, M. (2015), Patents and Cumulative Innovation: Causal Evidence from the Courts, The Quarterly Journal of Economics, 130 (1), 317-369

Guyon, N., Maurin, E. and McNally, S. (2012), The Effect of Tracking Students by Ability into Different Schools: A Natural Experiment, Journal of Human Resources, 47 (3), 684-721

Hanushek, E. and Woessmann, L. (2006), Does Educational Tracking affect Performance and Inequality? Differences-in-differences Evidence across Countries, The Economic Journal, 116, C63-C76

Heckman, J. and Vytlacil, E. (1999), Local Instrumental Variables and Latent Variable Models for Identifying and Bounding Treatment Effects, Proceedings of the National Academy of Sciences, 96 (8), 4730-4734

Heckman, J. and Vytlacil, E. (2005), Structural Equations, Treatment Effects, and Econometric Policy Evaluation, Econometrica, 73 (3), 669-738

Imbens, G. and Angrist, J. (1994), Identification and Estimation of Local Average Treatment Effects, Econometrica, 62 (2), 467-475

Koop, G. and Poirier, Dale J. (1997), Learning about the across-regime correlation in switching regression models, Journal of Econometrics, 78, 217-227

Lokshin, M. and Sajaia, Z. (2011), Impact of Interventions on Discrete Outcomes: Maximum Likelihood Estimation of the Binary Choice Models with Binary Endogenous Regressors, The Stata Journal, 11 (3), 368-385

Manski, C., Sandefur G., McLanahan, S. and Powers, D. (1992), Alternative Estimates of the Effect of Family Structure During Adolescence on High School Graduation, Journal of the American Statistical Association, 87 (417), 25-37

Mühlenweg, A. M. and Puhani, P. A. (2010), The Evolution of the School-Entry Age Effect in a School Tracking System, Journal of Human Resources, 45, 407-438

Nybom, M. (2017), The Distribution of Lifetime Earnings Returns to College, Journal of Labor Economics, 35 (4), 903-952

OECD (2018), Education at a Glance 2018: OECD Indicators, OECD Publishing, Paris

Oosterbeek, H., Ruijs, N. and de Wolf, I. (2020), Using Admission Lotteries to Estimate Heterogeneous Effects of Elite Schools, Tinbergen Institute Discussion Paper, TI 2020-018/V 
Pekkarinen, T., Uusitalo, R. and Kerr, S. (2009), School Tracking and Intergenerational Income Mobility: Evidence from the Finnish Comprehensive School Reform, Journal of Public Economics, 93 (7-8), 965-973

Pop-Eleches, C. and Urquiola, M. (2013), Going to a Better School: Effects and Behavioral Responses, American Economic Review, 103 (4), 1289-1324

Poirier, Dale J. and Tobias, Justin, L. (2003), On the Predictive Distributions of Outcome Gains in the Presence of an Unidentified Parameter, Journal of Business \& Economic Statistics, 21 (2), 258-268

Roller, M. and Steinberg, D. (2020), The distributional effects of early school stratification non-parametric evidence from Germany, European Economic Review, 125

Vademecum Statistische sectoren (2012), http://statbel.fgov.be/nl/binaries/Secteurs\%20statNL_tcm325-174181.pdf, [23/10/2015]

VDAB (2019), 32ste schoolverlatersrapport - editie 2019, https://www.vdab.be/sites/web/files/doc/schoolverlaters/schoolverlatersrapport2019.pdf Vytlacil, E. (2002), Independence, Monotonicity, and Latent Index Models: An Equivalence Result, Econometrica, 70 (1), 331-341 


\section{Appendix A: Construction of the dataset}

We obtained our main dataset from the Flemish Ministry of Education and observe information on 72,292 and 72,581 students who started for the first time in the first year of secondary education in 2003 and 2004, respectively. We observe students in administrative records until 2012 but we do not use the final year for the first cohort so that we observe students in both cohorts during nine consecutive years. We only keep students who start at the comprehensive program. In the first year, students can also start at a pre-vocational program. Students starting at this program often did not successfully complete their secondary education and therefore could not enroll in elite schools. This reduces our sample to 60,754 students in 2003 and 60,992 students in 2004. We also remove double entries, reducing the sample by 26 observations. Four students entered both an elite and non-elite school: we therefore remove them completely. Next, we remove students who do not live in one of the Flemish provinces. This reduces our sample to 59,092 and 59,824 students, respectively. ${ }^{44}$ Removing the observations with missing information about individual characteristics or detailed location reduces the sample to 55,527 and 56,252 observations, respectively.

We combine these data with data on neighborhood characteristics at the municipal and statistical sector level provided by ADSEI (now Statbel). From this data source, we use median income, average educational level, share of inhabitants with Belgian nationality, and population density. Most neighborhood characteristics are measured in 2001, before students enroll in secondary education. Median income is measured in 2004 because this is not available in the census of 2001. We merge the two datasets based on the statistical sector. A limited number of students cannot be merged and our sample reduces to 55,434 and 56,137 students for 2003 and 2004, respectively.

We observe for each student the study program in each year and the track as from grade 9. The track distinction does not officially exist before grade 9 but in grade 8 , students already choose a specific study program that prepares them for a specific track (we confirmed this by looking at common switching patterns). In practice, tracking thus occurs as from grade 8. Based on the study program, we can assign each student to a specific study program as from grade 8.

We observe the administrative number of the school and the exact location of the campus where the student is located. The administrative definition of a school does not always overlap with the actual school as it is perceived by parents and children. Large schools often

\footnotetext{
${ }^{44}$ Note that the province of Brabant was split in three parts in 1995. We still use the historical province of Brabant, which means we include the students of the Flemish province of Flemish Brabant, but also the students in Brussels and Walloon Brabant who attend Flemish schools.
} 
have several administrative entities at the same address, while other schools use the same administrative entity for schools in very different locations. We therefore use the address of the campus where the student is located to create an identifier for each school. We assign students to elite and non-elite schools based on the tracks that students actually choose at these schools. We can compute travel distance to schools based on the exact location of the school and the centroid of the statistical sector where the student lives.

We construct our outcome variables as follows. First, a student graduates from high school if he or she obtains a degree within nine years of studying. Since all schools appear in our dataset, we assume drop out from the data is drop out from the schooling system. Second, a student graduates without study delay if he or she obtains the degree within six years of studying. Finally, a student downgrades if he or she switches at least once to a lower ranked track.

\section{Appendix B: Sensitivity analysis}

In this appendix, we assess how sensitive our results are to the chosen sample of students, the composition of elite schools and the definition of obtaining a high school degree. The different treatment effects of choosing an elite school on high school completion are shown in Table B1. The first panel repeats the results from Table 5.

First, we restrict the sample to students for whom the exogeneity condition of the instrument is most likely to hold. Based on institutional grounds, we argue that distance is an exogenous instrument for school choice in Flanders when controlling for neighborhood characteristics. School choice is essentially free, and for most students several schools are located within commuting distance. From our dataset, we have computed that for the median student, six schools are located within a $5 \mathrm{~km}$ distance. Therefore, it seems unlikely that parents would base their location decision on a preference for certain schools. If our instrument is not exogenous, we expect this violation of the exogeneity assumption to be stronger in areas with fewer school alternatives, because parents may then decide to live closer to their preferred school. We assess this issue and repeat the analysis on a subsample of the data where we include only students who have at least four schooling options, located within a $5 \mathrm{~km}$ radius. Sensitivity check A in Table B1 shows that the treatment effects derived from the parametric model are almost identical to the treatment effects on the whole sample. The ATT is statistically insignificant and the ATNT and ATE are significantly positive. However, the ATT derived from the semi-parametric model is significantly positive for this alternative sample.

In sensitivity check B, we restrict the sample to students living close to elite schools and 
Table B1: Sensitivity analysis obtaining a high school degree: average treatment effects

\begin{tabular}{|c|c|c|c|c|}
\hline & \multicolumn{2}{|c|}{ Semi-parametric approach } & \multicolumn{2}{|c|}{ Parametric approach } \\
\hline & Coef. & St. error & Coef. & St. erro \\
\hline \multicolumn{5}{|c|}{ Main outcome: Obtaining a high school degree $(\mathrm{N}=111,571)$} \\
\hline ATT & 0.004 & $(0.019)$ & -0.016 & $(0.008)$ \\
\hline ATNT & \multicolumn{2}{|c|}{ Not identified ${ }^{a}$} & $0.051^{*}$ & $(0.010)$ \\
\hline ATE & \multicolumn{2}{|c|}{ Not identified ${ }^{a}$} & $0.033^{*}$ & $(0.008)$ \\
\hline \multicolumn{5}{|c|}{ Sensitivity A: Students with at least four schools within $5 \mathrm{~km}(\mathrm{~N}=76,580)$} \\
\hline ATT & $0.039^{*}$ & $(0.019)$ & -0.015 & $(0.011)$ \\
\hline ATNT & \multicolumn{2}{|c|}{ Not identified ${ }^{a}$} & $0.047^{*}$ & $(0.016)$ \\
\hline ATE & \multicolumn{2}{|c|}{ Not identified ${ }^{a}$} & $0.029^{*}$ & $(0.012)$ \\
\hline
\end{tabular}

Sensitivity B: Students with an elite school among the four closest schools $(\mathrm{N}=58,745)$

\begin{tabular}{|c|c|c|c|c|}
\hline ATT & -0.028 & $(0.051)$ & -0.029 & $(0.022)$ \\
\hline ATNT & & & 0.048 & $(0.037)$ \\
\hline ATE & & & 0.020 & $(0.024)$ \\
\hline
\end{tabular}

Sensitivity C: Students who choose the academic track $(\mathrm{N}=73,066)$

$\begin{array}{lllll}\text { ATT } & 0.026 & (0.015) & -0.008 & (0.007)\end{array}$

ATNT Not identified $^{a} \quad 0.028^{*} \quad(0.007)$

ATE Not identified $^{a} \quad 0.014^{*} \quad(0.005)$

Sensitivity D: Students in schools that offer the academic track $(\mathrm{N}=97,297)$

$\begin{array}{lllll}\text { ATT } & 0.014 & (0.019) & -0.012 & (0.007)\end{array}$

ATNT Not identified $^{a} \quad 0.046^{*} \quad(0.010)$

ATE Not identified $^{a} \quad 0.028^{*} \quad(0.007)$

Sensitivity E: Students still in school after three years of study delay omitted $(\mathrm{N}=111,275)$

\begin{tabular}{|c|c|c|c|c|}
\hline ATT & -0.001 & $(0.018)$ & $-0.018^{*}$ & $(0.008)$ \\
\hline ATNT & & & $0.049^{*}$ & $(0.010)$ \\
\hline ATE & & & $0.031^{*}$ & $(0.008)$ \\
\hline
\end{tabular}

Sensitivity F: Students still in school after three years of study delay classified as graduated $(\mathrm{N}=111,571)$

$\begin{array}{llll}\text { ATT } & -0.002 & (0.018) & -0.018^{*}\end{array}$

ATNT Not identified $^{a} \quad 0.049^{*} \quad(0.011)$

ATE $\quad{\text { Not } \text { identified }^{a}}^{a} \quad 0.031^{*} \quad(0.008)$

Note: Standard errors are corrected for clustering within the statistical sector and computed with a bootstrap procedure using 250 replications. $\quad 39$

* Statistical significance at $5 \%$ level.

${ }^{a}$ Not identified due to insufficient common support. 
consider only students who have at least one elite school among the four closest schooling options. If parents base their location decision on the availability of elite schools and move to an area with an elite school, we would expect that the exogeneity condition of the instrument is least likely to hold for students living in neighborhoods close to these schools. Similar to our main specification, we obtain a statistically insignificant ATT in both approaches. The ATE and ATNT derived from the parametric model are similar to the estimates from the main specification, but less precisely estimated due to the smaller sample size.

In sensitivity check $\mathrm{C}$, we restrict the sample to students starting the academic track in the second grade of high school. This removes a large number of students, primarily in the non-elite schools. Many of them are possibly not interested in staying in an elite school if they would go there in the first year, as they are not willing to enroll in the academic track. It could therefore generate more precise estimates by focusing on a more relevant group of students. At the same time, it also removes some students who did want to enroll in the academic track before they made their school choice but decided not to (or were not permitted to). Note that we found that the elite school itself has a positive impact on choosing the academic track for non-treated students and this improves their outcome. We should therefore expect a less positive effect by removing these students as we are ignoring part of the effect of an elite school. Indeed, the effects for the non-treated are smaller but more precisely estimated in this restricted sample.

In sensitivity check $\mathrm{D}$, we assess whether or not our results are robust to a different composition of non-elite schools. There exist two different types of non-elite schools. The first type are the general schools that offer programs in the academic track in combination with technical, artistic or vocational programs. Most first year students (60.5\%) enroll at this type of schools. The second type of schools specialize in technical, artistic and/or vocational programs and do not offer academic programs. These schools have a small share of first year enrollment (12.8\%). As students who start at a non-elite school without programs in the academic track can differ from students who start at the first type of non-elite schools, we repeat the analysis and include only students who started at an elite school and students who started at a non-elite school that also offers the academic track. We obtain similar results as in our main specification.

In the last two panels of Table B1, we assess whether or not our results are affected by our assumptions on high school graduation. We observe students for a maximum of nine years in high school: $0.3 \%$ of the students have not obtained a degree at the end of the ninth year and are still enrolled in high school. As our main outcome variable is high school completion, we considered these students as high school drop-outs in our previous analysis. We assess whether or not our results are affected by this assumption and remove these 
students from the data in sensitivity check E. In sensitivity check F, we assume that these students eventually obtain a high school degree and consider them as high school graduates. The last two panels in Table B1 show that our results do not change when imposing other assumptions on the study outcomes of these students.

\section{Appendix C: Role of control variables}

In this appendix, we assess how including neighborhood characteristics affects the treatment effects of choosing an elite school on high school completion. Table C1 summarizes the treatment effects based on the parametric model for several specifications with alternative sets of control variables. When including only student characteristics we find an ATT of -4.6 percentage points that is statistically significantly different from zero. The ATE and ATNT are precisely estimated around 0 . The effect of an elite school improves substantially when we add a small set of dummy variables that capture the different location of students: four categories of urbanization of the municipality and five dummy variables for provinces. The ATT is now only -1.9 percentage points and the ATE and ATNT become statistically significant, with positive treatment effects of 2.3 and 3.9 percentage points. Adding additional characteristics at the municipality level hardly affects the ATT and slightly increases the ATE and ATNT. In the last specification (which is the one we use in the paper) we also control for demographics at the statistical sector level which changes little to the results.

In Table C2 we show the impact of student characteristics on relative distance when controlling for different sets of regional characteristics. The first specification shows that individual characteristics explain only a small part of the variation $\left(\mathrm{R}^{2}=0.006\right)$. Effect sizes are relatively small too, but the large sample size does allow us to detect statistically significant effects that can be informative to learn about a potential bias in the estimates when we do not control for neighborhood characteristics. Importantly, we see that students who repeated a grade before entering secondary education live 263 meters closer to an elite school. This might seem like a small distance, but it is statistically significant. We interpret this as an indication that students of lower ability live closer to elite schools. Since this dummy variable is only a very rough proxy of ability, controlling for it is not sufficient to obtain reliable estimates of treatment effects. After controlling for province and urbanization

fixed effects $(F E)$, we explain much more of the variation $\left(\mathrm{R}^{2}=0.142\right)$ and the effect of grade repetition on the instrument reduces to a very small and statistically insignificant 10 meters. This suggests that we are now better controlling for local differences in ability. Consistent with this, we observe a strong improvement in the estimated effect of elite schools in Table $\mathrm{C} 1$. Other controls for neighborhood characteristics help to further reduce the correlation 
between socioeconomic characteristics and the instrument, but this has much smaller effects on the estimates of the treatment effects.

We conclude that Flanders is not sufficiently homogeneous to rely on distance as an instrument for school choice without controlling for the broad differences between provinces and levels of urbanization. Descriptive statistics show that proportionally more students of lower ability are living in urban areas and that elite schools are more accessible for students living in these areas. For example, $93 \%$ of the 75,595 students living in the most rural municipalities graduate from high school while this is only $86 \%$ for the 15,808 students living in the largest cities. $9 \%$ of students repeated a grade before entering secondary education in the rural areas, while this is $19 \%$ in the largest cities. Meanwhile, the average difference in distance to an elite school is only 835 meters for students living in the largest cities and 3013 meters for students living in the most rural municipalities. This is not surprising, as a larger number of potential students in urban municipalities allows for more variety in school choice and the possibility for schools to specialize in a track. It is therefore much easier to access an elite school for students living in urban areas, explaining why $38 \%$ of them go to an elite school. In rural municipalities this is only $24 \%$. Without including controls for the different types of municipalities, the estimator links lower performance in urban municipalities (which are likely due to other factors than elite schools) with the easier access to elite schools, leading to an underestimation of the treatment effects.

Table C1: The role of control variables: average treatment effects

\begin{tabular}{|c|c|c|c|c|c|c|c|c|}
\hline & \multicolumn{2}{|c|}{ (1) } & \multicolumn{2}{|c|}{$(2)$} & \multicolumn{2}{|c|}{ (3) } & \multicolumn{2}{|c|}{$(4)$} \\
\hline & Coef. & St. error & Coef. & St. error & Coef. & St. error & Coef. & St. error \\
\hline ATT & $-0.046^{*}$ & $(0.004)$ & $-0.019 *$ & $(0.008)$ & -0.015 & $(0.009)$ & -0.016 & $(0.008)$ \\
\hline ATNT & 0.005 & $(0.014)$ & $0.039^{*}$ & $(0.010)$ & $0.047^{*}$ & $(0.010)$ & $0.051^{*}$ & $(0.011)$ \\
\hline ATE & -0.009 & $(0.011)$ & $0.023^{*}$ & $(0.008)$ & $0.030^{*}$ & $(0.008)$ & $0.033^{*}$ & $(0.009)$ \\
\hline Student characteristics & \multicolumn{2}{|c|}{ yes } & \multicolumn{2}{|c|}{ yes } & \multicolumn{2}{|c|}{ yes } & \multicolumn{2}{|c|}{ yes } \\
\hline Province and urbanization FE & \multicolumn{2}{|c|}{ no } & \multicolumn{2}{|c|}{ yes } & \multicolumn{2}{|c|}{ yes } & \multicolumn{2}{|c|}{ yes } \\
\hline Neighborhood characteristics & \multicolumn{2}{|c|}{ no } & \multicolumn{2}{|c|}{ no } & \multicolumn{2}{|c|}{ municipality } & \multicolumn{2}{|c|}{$\begin{array}{c}\text { municipality }+ \\
\text { statistical sector }\end{array}$} \\
\hline
\end{tabular}

Note: Average treatment effects are calculated based on 111,571 students. Standard errors are corrected for clustering within the statistical sector and computed by sampling 250 draws from the estimated distribution. For each draw of the estimates we calculate the treatment effects by simulating the error terms of the potential outcome framework (100 draws for each student).

* Statistical significance at $5 \%$ level. 
Table C2: The role of control variables: regression of relative distance on student characteristics

\begin{tabular}{|c|c|c|c|c|c|c|c|c|}
\hline \multirow[t]{2}{*}{ Variables } & \multicolumn{2}{|c|}{ (1) } & \multicolumn{2}{|c|}{$(2)$} & \multicolumn{2}{|c|}{ (3) } & \multicolumn{2}{|c|}{ (4) } \\
\hline & Coef. & St. error & Coef. & St. error & Coef. & St. error & Coef. & St. error \\
\hline Mother no high school degree ${ }^{a}$ & $-0.437^{*}$ & $(0.047)$ & $-0.349^{*}$ & $(0.041)$ & $-0.101^{*}$ & $(0.038)$ & -0.055 & $(0.033)$ \\
\hline Mother high school degree ${ }^{a}$ & $-0.370^{*}$ & $(0.033)$ & $-0.224^{*}$ & $(0.030)$ & $-0.055^{*}$ & $(0.027)$ & -0.023 & $(0.024)$ \\
\hline No Dutch at home & $0.803^{*}$ & $(0.083)$ & $0.158^{*}$ & $(0.069)$ & 0.092 & $(0.068)$ & 0.040 & $(0.062)$ \\
\hline Low income & $-0.135^{*}$ & $(0.037)$ & $-0.124^{*}$ & $(0.032)$ & $-0.062^{*}$ & $(0.031)$ & -0.046 & $(0.030)$ \\
\hline Male & -0.009 & $(0.021)$ & -0.006 & $(0.019)$ & -0.012 & $(0.019)$ & -0.010 & $(0.019)$ \\
\hline Repeated & $0.263^{*}$ & $(0.039)$ & 0.010 & $(0.034)$ & -0.028 & $(0.032)$ & -0.025 & $(0.032)$ \\
\hline Province and urbanization FE & \multicolumn{2}{|c|}{ no } & \multicolumn{2}{|c|}{ yes } & \multicolumn{2}{|c|}{ yes } & \multicolumn{2}{|c|}{ yes } \\
\hline Neighborhood characteristics & \multicolumn{2}{|c|}{ no } & \multicolumn{2}{|c|}{ no } & \multicolumn{2}{|c|}{ municipality } & \multicolumn{2}{|c|}{$\begin{array}{c}\text { municipality }+ \\
\text { statistical sector }\end{array}$} \\
\hline F-test individual characteristics & \multicolumn{2}{|c|}{$49.81(\mathrm{p}=0.000)$} & \multicolumn{2}{|c|}{$16.60(\mathrm{p}=0.000)$} & \multicolumn{2}{|c|}{$2.52(\mathrm{p}=0.0195)$} & \multicolumn{2}{|c|}{$1.28(\mathrm{p}=0.263)$} \\
\hline $\mathrm{R}^{2}$ & \multicolumn{2}{|c|}{0.006} & \multicolumn{2}{|c|}{0.142} & \multicolumn{2}{|c|}{0.183} & \multicolumn{2}{|c|}{0.185} \\
\hline Observations & \multicolumn{2}{|c|}{111,571} & \multicolumn{2}{|c|}{111,571} & \multicolumn{2}{|c|}{111,571} & \multicolumn{2}{|c|}{111,571} \\
\hline
\end{tabular}

Note: Standard errors are corrected for clustering within the statistical sector.

* Statistical significance at $5 \%$ level.

${ }^{a}$ Base category $=$ mother has a degree in higher education.

\section{Appendix D: Additional tables and figures}


Table D1: Obtaining a high school degree: OLS and 2SLS

\begin{tabular}{|c|c|c|c|c|c|c|c|c|}
\hline \multirow[b]{3}{*}{ Variables } & \multicolumn{4}{|c|}{ OLS } & \multicolumn{4}{|c|}{ 2SLS } \\
\hline & \multicolumn{2}{|c|}{ (1) } & \multicolumn{2}{|c|}{$(2)$} & \multicolumn{2}{|c|}{$(3)$} & \multicolumn{2}{|c|}{$(4)$} \\
\hline & Coef. & St. error & Coef. & St. error & Coef. & St. error & Coef. & St. error \\
\hline Elite school & $0.039 *$ & $(0.002)$ & $0.018^{*}$ & $(0.002)$ & -0.005 & $(0.010)$ & -0.009 & $(0.010)$ \\
\hline Mother no high school ${ }^{a}$ & & & $-0.086^{*}$ & $(0.003)$ & & & $-0.091^{*}$ & $(0.003)$ \\
\hline Mother high school $^{a}$ & & & $-0.032^{*}$ & $(0.002)$ & & & $-0.036^{*}$ & $(0.002)$ \\
\hline No Dutch at home & & & $-0.046^{*}$ & $(0.006)$ & & & $-0.044^{*}$ & $(0.006)$ \\
\hline Low income & & & -0.001 & $(0.002)$ & & & -0.002 & $(0.002)$ \\
\hline Male & & & $-0.048^{*}$ & $(0.002)$ & & & $-0.048^{*}$ & $(0.002)$ \\
\hline Repeated & & & $-0.097^{*}$ & $(0.004)$ & & & $-0.101^{*}$ & $(0.004)$ \\
\hline Constant & $0.730^{*}$ & $(0.028)$ & $0.902^{*}$ & $(0.027)$ & $0.770^{*}$ & $(0.030)$ & $0.932^{*}$ & $(0.029)$ \\
\hline Neighborhood characteristics & \multicolumn{2}{|c|}{ yes } & \multicolumn{2}{|c|}{ yes } & \multicolumn{2}{|c|}{ yes } & \multicolumn{2}{|c|}{ yes } \\
\hline Observations & \multicolumn{2}{|c|}{111,571} & \multicolumn{2}{|c|}{111,571} & \multicolumn{2}{|c|}{111,571} & \multicolumn{2}{|c|}{111,571} \\
\hline
\end{tabular}

Note: Standard errors are corrected for clustering within the statistical sector. Neighborhood characteristics include population density, median household income, the share of Belgians and average educational level at the municipality and the statistical sector. All regressions additionally control for province fixed effects and indicators for the level of urbanization of the municipality.

* Statistical significance at $5 \%$ level.

${ }^{a}$ Base category $=$ mother has a degree in higher education.

Figure D1: Weights for the calculation of the ATT

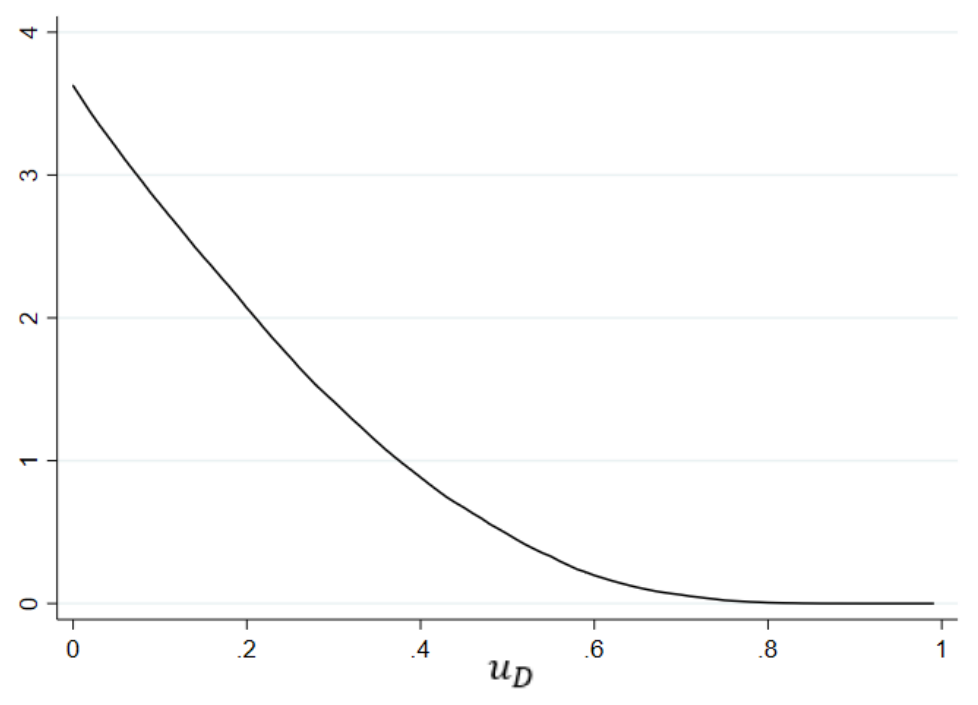


Table D2: Obtaining a high school degree: estimation results semi-parametric approach

\begin{tabular}{|c|c|c|c|c|c|c|}
\hline \multirow[b]{3}{*}{ Variables } & \multirow{2}{*}{\multicolumn{2}{|c|}{$\begin{array}{l}\text { Selection equation } \\
\text { Index prop. score }\end{array}$}} & \multicolumn{4}{|c|}{ Outcome equation } \\
\hline & & & \multicolumn{2}{|c|}{ Baseline effect } & \multicolumn{2}{|c|}{ Difference if treated } \\
\hline & Coef. & St. error & Coef. & St. error & Coef. & St. error \\
\hline Relative distance & $0.131^{*}$ & $(0.004)$ & & & & \\
\hline Mother no high school ${ }^{a}$ & $-0.659^{*}$ & $(0.015)$ & $-0.087^{*}$ & $(0.005)$ & 0.026 & $(0.024)$ \\
\hline Mother high school ${ }^{a}$ & $-0.406^{*}$ & $(0.010)$ & $-0.030^{*}$ & $(0.003)$ & -0.008 & $(0.011)$ \\
\hline No Dutch at home & $0.251^{*}$ & $(0.025)$ & $-0.025^{*}$ & $(0.010)$ & $-0.075^{*}$ & $(0.024)$ \\
\hline Low income & $-0.119 *$ & $(0.013)$ & 0.006 & $(0.004)$ & -0.030 & $(0.016)$ \\
\hline Male & $-0.042^{*}$ & $(0.010)$ & $-0.056^{*}$ & $(0.003)$ & $0.030^{*}$ & $(0.008)$ \\
\hline Repeated & $-0.496^{*}$ & $(0.018)$ & $-0.100^{*}$ & $(0.006)$ & 0.050 & $(0.029)$ \\
\hline Neighborhood characteristics & \multicolumn{2}{|c|}{ yes } & \multicolumn{2}{|c|}{ yes } & \multicolumn{2}{|c|}{ yes } \\
\hline $\mathrm{P}$-value no observable heterogeneity & \multicolumn{2}{|c|}{0.000} & & & & \\
\hline P-value no unobservable heterogeneity & \multicolumn{2}{|c|}{0.424} & & & & \\
\hline Observations & \multicolumn{2}{|c|}{111,571} & & & & \\
\hline
\end{tabular}

Note: Standard errors are corrected for clustering within the statistical sector. The results are obtained from a semi-parametric approach which follows the approach described in Section 4.3 of Cornelissen et al. (2016) (pp. 55-56). The estimates of "Baseline effect" correspond to $\beta_{0}$ in their equation (26), while "Difference if treated" corresponds to $\beta_{1}-\beta_{0}$. The reported test statistic for observable heterogeneity tests for joint significance of all elements in the vector $\beta_{1}-\beta_{0}$, while the test for unobservable heterogeneity tests if MTEs differ with unobserved costs of treatment. We estimated the model in STATA with the userwritten command "mtefe" (Andresen, 2018).

* Statistical significance at $5 \%$ level.

${ }^{a}$ Base category $=$ mother has a degree in higher education. 
Table D3: Obtaining a high school degree: estimation results parametric approach

\begin{tabular}{|c|c|c|c|c|c|c|}
\hline \multirow[b]{3}{*}{ Variables } & \multirow{2}{*}{\multicolumn{2}{|c|}{$\begin{array}{c}\text { Selection equation } \\
\text { elite school }\end{array}$}} & \multicolumn{4}{|c|}{ Outcome equations } \\
\hline & & & \multicolumn{2}{|c|}{ elite school } & \multicolumn{2}{|c|}{ non-elite school } \\
\hline & Coef. & St. error & Coef. & St. error & Coef. & St. error \\
\hline Relative distance & $0.131^{*}$ & $(0.004)$ & & & & \\
\hline Mother no high school ${ }^{a}$ & $-0.659^{*}$ & $(0.015)$ & $-0.457^{*}$ & $(0.051)$ & $-0.632 *$ & $(0.021)$ \\
\hline Mother high school $^{a}$ & $-0.406^{*}$ & $(0.010)$ & $-0.293^{*}$ & $(0.035)$ & $-0.326^{*}$ & $(0.018)$ \\
\hline No Dutch at home & $0.253^{*}$ & $(0.025)$ & $-0.290^{*}$ & $(0.048)$ & $-0.131^{*}$ & $(0.029)$ \\
\hline Low income & $-0.118^{*}$ & $(0.013)$ & -0.064 & $(0.035)$ & -0.004 & $(0.016)$ \\
\hline Male & $-0.042^{*}$ & $(0.010)$ & $-0.413^{*}$ & $(0.027)$ & $-0.343^{*}$ & $(0.013)$ \\
\hline Repeated & $-0.496^{*}$ & $(0.018)$ & $-0.458^{*}$ & $(0.051)$ & $-0.473^{*}$ & $(0.018)$ \\
\hline Constant & $2.388^{*}$ & $(0.261)$ & $1.831^{*}$ & $(0.417)$ & $1.844^{*}$ & $(0.222)$ \\
\hline Neighborhood characteristics & \multicolumn{2}{|c|}{ yes } & \multicolumn{2}{|c|}{ yes } & \multicolumn{2}{|c|}{ yes } \\
\hline$\rho_{1}$ & $-0.185^{*}$ & $(0.070)$ & & & & \\
\hline$\rho_{0}$ & $0.193^{*}$ & $(0.058)$ & & & & \\
\hline Log likelihood & \multicolumn{2}{|c|}{-82068} & & & & \\
\hline Observations & \multicolumn{2}{|c|}{111,571} & & & & \\
\hline
\end{tabular}

Note: Standard errors are corrected for clustering within the statistical sector. The results are obtained from a parametric model where we assume that the error terms are jointly normally distributed. We estimated the model in STATA with the user-written command "switch_probit" (Lokshin and Sajaia, 2011).

* Statistical significance at $5 \%$ level.

${ }^{a}$ Base category $=$ mother has a degree in higher education. 
Table D4: Graduating without study delay: average treatment effects

\begin{tabular}{lcccc}
\hline & \multicolumn{2}{l}{ Semi-parametric approach } & \multicolumn{2}{c}{ Parametric approach } \\
& Coef. & \multicolumn{1}{c}{ St. error } & Coef. & St. error \\
\hline ATT & 0.016 & $(0.030)$ & -0.010 & $(0.018)$ \\
ATNT & \multicolumn{2}{c}{ Not identified $^{a}$} & $0.112^{*}$ & $(0.020)$ \\
ATE & \multicolumn{2}{rl}{${\text { Not } \text { identified }^{a}}^{2}$} & $0.080^{*}$ & $(0.016)$ \\
\hline
\end{tabular}

Note: Average treatment effects are calculated based on 111,571 students. Standard errors are corrected for clustering within the statistical sector and computed with a bootstrap procedure using 250 replications. Average outcome in sample: 0.775 (Elite), 0.700 (non-elite).

* Statistical significance at $5 \%$ level.

${ }^{a}$ Not identified due to insufficient common support.

Figure D2: Graduating without study delay: MTE

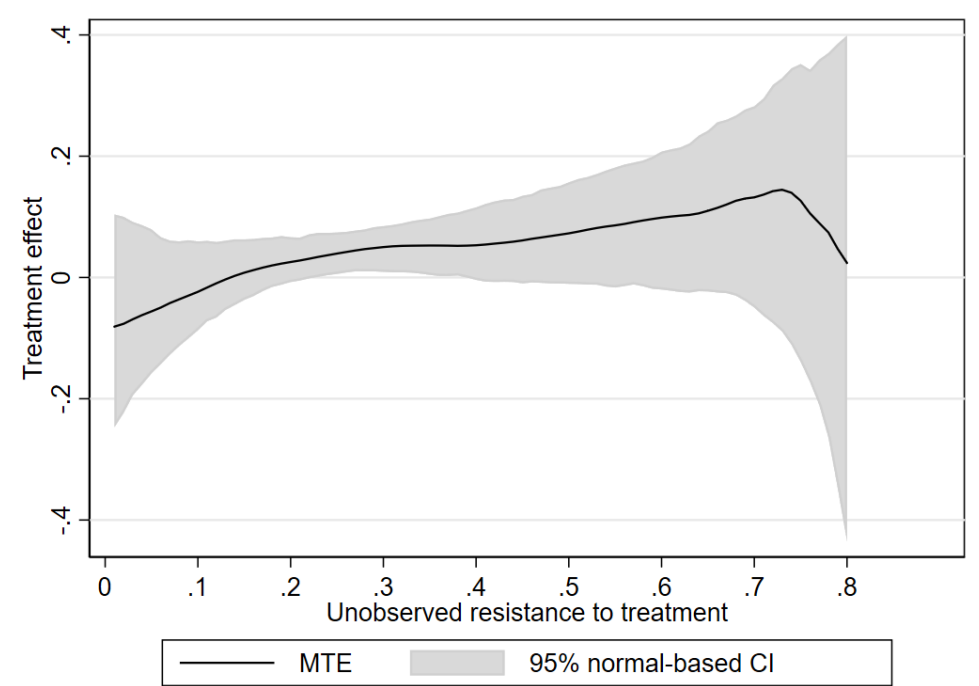

Note: MTEs are calculated based on 111,571 students using a local polynomial regression of degree 2 with an Epanechnikov kernel. Standard errors are computed with a bootstrap procedure (250 replications) and clustered within the statistical sector. P-value no observable heterogeneity (0.000), p-value no unobservable heterogeneity (0.882). 
Table D5: Graduating without study delay: estimation results semi-parametric approach

\begin{tabular}{|c|c|c|c|c|c|c|}
\hline \multirow[b]{3}{*}{ Variables } & \multirow{2}{*}{\multicolumn{2}{|c|}{$\begin{array}{l}\text { Selection equation } \\
\text { Index prop. score }\end{array}$}} & \multicolumn{4}{|c|}{ Outcome equation } \\
\hline & & & \multicolumn{2}{|c|}{ Baseline effect } & \multicolumn{2}{|c|}{ Difference if treated } \\
\hline & Coef. & St. error & Coef. & St. error & Coef. & St. error \\
\hline Relative distance & $0.131^{*}$ & $(0.004)$ & & & & \\
\hline Mother no high school ${ }^{a}$ & $-0.659^{*}$ & $(0.015)$ & $-0.162^{*}$ & $(0.007)$ & -0.004 & $(0.035)$ \\
\hline Mother high school $^{a}$ & $-0.406^{*}$ & $(0.010)$ & $-0.082^{*}$ & $(0.006)$ & -0.040 & $(0.021)$ \\
\hline No Dutch at home & $0.251^{*}$ & $(0.025)$ & $-0.093^{*}$ & $(0.013)$ & -0.011 & $(0.034)$ \\
\hline Low income & $-0.119^{*}$ & $(0.013)$ & -0.009 & $(0.006)$ & $-0.055^{*}$ & $(0.021)$ \\
\hline Male & $-0.042^{*}$ & $(0.010)$ & $-0.149^{*}$ & $(0.004)$ & 0.162 & $(0.013)$ \\
\hline Repeated & $-0.496^{*}$ & $(0.018)$ & $-0.042^{*}$ & $(0.007)$ & -0.035 & $(0.035)$ \\
\hline Neighborhood characteristics & \multicolumn{2}{|c|}{ yes } & \multicolumn{2}{|c|}{ yes } & \multicolumn{2}{|c|}{ yes } \\
\hline P-value no observable heterogeneity & \multicolumn{2}{|c|}{0.000} & & & & \\
\hline $\mathrm{P}$-value no unobservable heterogeneity & \multicolumn{2}{|c|}{0.882} & & & & \\
\hline Observations & \multicolumn{2}{|c|}{111,571} & & & & \\
\hline
\end{tabular}

Note: Standard errors are corrected for clustering within the statistical sector. The results are obtained from a semi-parametric approach which follows the approach described in Section 4.3 of Cornelissen et al. (2016) (pp. 55-56). The estimates of "Baseline effect" correspond to $\beta_{0}$ in their equation (26), while "Difference if treated" corresponds to $\beta_{1}-\beta_{0}$. The reported test statistic for observable heterogeneity tests for joint significance of all elements in the vector $\beta_{1}-\beta_{0}$, while the test for unobservable heterogeneity tests if MTEs differ with unobserved costs of treatment. We estimated the model in STATA with the userwritten command "mtefe" (Andresen, 2018).

* Statistical significance at $5 \%$ level.

${ }^{a}$ Base category $=$ mother has a degree in higher education. 
Table D6: Graduating without study delay: estimation results parametric approach

\begin{tabular}{|c|c|c|c|c|c|c|}
\hline \multirow[b]{3}{*}{ Variables } & \multirow{2}{*}{\multicolumn{2}{|c|}{$\begin{array}{c}\text { Selection equation } \\
\text { elite school }\end{array}$}} & \multicolumn{4}{|c|}{ Outcome equations } \\
\hline & & & \multicolumn{2}{|c|}{ elite school } & \multicolumn{2}{|c|}{ non-elite school } \\
\hline & Coef. & St. error & Coef. & St. error & Coef. & St. error \\
\hline Relative distance & $0.131^{*}$ & $(0.004)$ & & & & \\
\hline Mother no high school ${ }^{a}$ & $-0.659^{*}$ & $(0.015)$ & $-0.512^{*}$ & $(0.037)$ & $-0.539 *$ & $(0.159)$ \\
\hline Mother high school $^{a}$ & $-0.405^{*}$ & $(0.011)$ & $-0.318^{*}$ & $(0.024)$ & $-0.318^{*}$ & $(0.013)$ \\
\hline No Dutch at home & $0.251^{*}$ & $(0.025)$ & $-0.307^{*}$ & $(0.039)$ & $-0.227^{*}$ & $(0.025)$ \\
\hline Low income & $-0.118^{*}$ & $(0.013)$ & $-0.122^{*}$ & $(0.025)$ & $-0.054^{*}$ & $(0.012)$ \\
\hline Male & $-0.042^{*}$ & $(0.010)$ & $-0.501^{*}$ & $(0.018)$ & $-0.454^{*}$ & $(0.010)$ \\
\hline Repeated & $-0.496^{*}$ & $(0.018)$ & $-0.212^{*}$ & $(0.040)$ & $-0.146^{*}$ & $(0.016)$ \\
\hline Constant & $2.384^{*}$ & $(0.261)$ & $0.894^{*}$ & $(0.287)$ & $0.788^{*}$ & $(0.175)$ \\
\hline Neighborhood characteristics & \multicolumn{2}{|c|}{ yes } & \multicolumn{2}{|c|}{ yes } & \multicolumn{2}{|c|}{ yes } \\
\hline$\rho_{1}$ & $-0.172^{*}$ & $(0.047)$ & & & & \\
\hline$\rho_{0}$ & $0.137^{*}$ & $(0.037)$ & & & & \\
\hline Log likelihood & \multicolumn{2}{|c|}{-114367} & & & & \\
\hline Observations & \multicolumn{2}{|c|}{111,571} & & & & \\
\hline
\end{tabular}

Note: Standard errors are corrected for clustering within the statistical sector. The results are obtained from a parametric model where we assume that the error terms are jointly normally distributed. We estimated the model in STATA with the user-written command "switch_probit" (Lokshin and Sajaia, 2011).

* Statistical significance at $5 \%$ level.

${ }^{a}$ Base category $=$ mother has a degree in higher education. 
Table D7: Extended model: estimation results selection equations

\begin{tabular}{|c|c|c|c|c|c|c|}
\hline \multirow[b]{3}{*}{ Variables } & \multicolumn{2}{|c|}{$\begin{array}{c}\text { Selection equation } \\
\text { elite school }\end{array}$} & \multicolumn{4}{|c|}{$\begin{array}{c}\text { Selection equation } \\
\text { academic track }\end{array}$} \\
\hline & \multirow[b]{2}{*}{ Coef. } & \multirow[b]{2}{*}{ St. error } & \multicolumn{2}{|c|}{ after non-elite } & \multicolumn{2}{|c|}{ after elite } \\
\hline & & & Coef. & St. error & Coef. & St. error \\
\hline Relative distance elite school & $0.206^{*}$ & $(0.006)$ & & & & \\
\hline Relative distance academic track & $-0.103^{*}$ & $(0.014)$ & $0.032^{*}$ & $(0.011)$ & -0.015 & $(0.016)$ \\
\hline Mother no high school ${ }^{a}$ & $-0.931^{*}$ & $(0.021)$ & $-1.268^{*}$ & $(0.042)$ & $-0.889^{*}$ & $(0.085)$ \\
\hline Mother high school $^{a}$ & $-0.573^{*}$ & $(0.015)$ & $-0.879^{*}$ & $(0.030)$ & $-0.524^{*}$ & $(0.054)$ \\
\hline No Dutch at home & $0.356^{*}$ & $(0.036)$ & $0.559^{*}$ & $(0.039)$ & -0.012 & $(0.059)$ \\
\hline Low income & $-0.164^{*}$ & $(0.018)$ & $-0.135^{*}$ & $(0.016)$ & $-0.163^{*}$ & $(0.037)$ \\
\hline Male & $-0.063^{*}$ & $(0.014)$ & $-0.309^{*}$ & $(0.014)$ & $-0.220^{*}$ & $(0.027)$ \\
\hline Repeated & $-0.693^{*}$ & $(0.025)$ & $-1.192^{*}$ & $(0.041)$ & $-0.839^{*}$ & $(0.071)$ \\
\hline Factor loading & 1 & (.) & $0.870^{*}$ & $(0.058)$ & 0.251 & $(0.156)$ \\
\hline Neighborhood characteristics & \multicolumn{2}{|c|}{ yes } & \multicolumn{2}{|c|}{ yes } & \multicolumn{2}{|c|}{ yes } \\
\hline Log likelihood & \multicolumn{2}{|c|}{-137321} & & & & \\
\hline Observations & \multicolumn{2}{|c|}{111,571} & & & & \\
\hline
\end{tabular}

Note: Standard errors are corrected for clustering within the statistical sector. The results are

obtained from a factor model. We estimated the model with the STATA command "gsem". Effects

of neighborhood characteristics on track constrained to be the same, regardless of elite

school choice.

* Statistical significance at $5 \%$ level.

${ }^{a}$ Base category $=$ mother has a degree in higher education. 
Table D8: Extended model: estimation results outcome equations

\begin{tabular}{|c|c|c|c|c|c|c|c|c|}
\hline \multirow[b]{4}{*}{ Variables } & \multicolumn{8}{|c|}{ Outcome equations } \\
\hline & \multicolumn{4}{|c|}{ Academic track } & \multicolumn{4}{|c|}{ Other track } \\
\hline & \multicolumn{2}{|c|}{ elite school } & \multicolumn{2}{|c|}{ non-elite school } & \multicolumn{2}{|c|}{ elite school } & \multicolumn{2}{|c|}{ non-elite school } \\
\hline & Coef. & St. error & Coef. & St. error & Coef. & St. error & Coef. & St. error \\
\hline \multicolumn{9}{|l|}{ Relative distance elite school } \\
\hline \multicolumn{9}{|c|}{ Relative distance academic track } \\
\hline Mother no high school ${ }^{a}$ & $-0.379^{*}$ & $(0.052)$ & $-0.537^{*}$ & $(0.054)$ & -0.224 & $(0.119)$ & $-0.558^{*}$ & $(0.071)$ \\
\hline Mother high school $^{a}$ & $-0.254^{*}$ & $(0.035)$ & $-0.302^{*}$ & $(0.039)$ & -0.143 & $(0.097)$ & $-0.244^{*}$ & $(0.052)$ \\
\hline No Dutch at home & $-0.367^{*}$ & $(0.056)$ & $-0.181^{*}$ & $(0.046)$ & -0.097 & $(0.119)$ & $-0.138^{*}$ & $(0.043)$ \\
\hline Low income & -0.071 & $(0.040)$ & $-0.086^{*}$ & $(0.027)$ & 0.077 & $(0.082)$ & $0.050^{*}$ & $(0.021)$ \\
\hline Male & $-0.412^{*}$ & $(0.030)$ & $-0.438^{*}$ & $(0.024)$ & $-0.392^{*}$ & $(0.073)$ & $-0.269^{*}$ & $(0.023)$ \\
\hline Repeated & $-0.394^{*}$ & $(0.055)$ & $-0.497^{*}$ & $(0.055)$ & $-0.207^{*}$ & $(0.100)$ & $-0.395^{*}$ & $(0.053)$ \\
\hline Factor loading & $-0.247^{*}$ & $(0.116)$ & 0.147 & $(0.087)$ & $-0.448^{*}$ & $(0.150)$ & 0.186 & $(0.129)$ \\
\hline Neighborhood characteristics & \multicolumn{2}{|c|}{ yes } & \multicolumn{2}{|c|}{ yes } & \multicolumn{2}{|c|}{ yes } & \multicolumn{2}{|c|}{ yes } \\
\hline Log likelihood & -137321 & & & & & & & \\
\hline Observations & 111,571 & & & & & & & \\
\hline
\end{tabular}

Note: Standard errors are corrected for clustering within the statistical sector. The results are obtained from a factor model. We estimate the model with the STATA command "gsem". Effects of neighborhood characteristics on outcome constrained to be the same for each track choice but allowed to differ by school choice.

* Statistical significance at $5 \%$ level.

${ }^{a}$ Base category $=$ mother has a degree in higher education. 
Table D9: Extended model using track in grade 9: average treatment effects

\begin{tabular}{|c|c|c|c|c|c|c|}
\hline & Coef. & St. error & Coef. & St. error & Coef. & St. error \\
\hline Treatment & \multicolumn{2}{|c|}{ Elite school } & \multicolumn{2}{|c|}{ Academic track } & \multicolumn{2}{|c|}{ Elite school } \\
\hline Outcome & \multicolumn{2}{|c|}{ High school degree } & \multicolumn{2}{|c|}{ High school degree } & \multicolumn{2}{|c|}{ Academic track } \\
\hline ATT & -0.010 & $(0.008)$ & $0.072^{*}$ & $(0.009)$ & $0.070^{*}$ & $(0.011)$ \\
\hline ATNT & $0.048^{*}$ & $(0.010)$ & $0.069^{*}$ & $(0.010)$ & $0.175^{*}$ & $(0.030)$ \\
\hline ATE & $0.032 *$ & $(0.008)$ & $0.072^{*}$ & $(0.008)$ & $0.147^{*}$ & $(0.024)$ \\
\hline
\end{tabular}

Note: Average treatment effects are calculated based on 111,571 students. Standard errors are corrected for clustering within the statistical sector and computed by sampling 250 draws from the estimated distribution. For each draw of the estimates we calculate the treatment effects by simulating the error terms of the potential outcome framework (100 draws for each student).

* Statistical significance at $5 \%$ level.

Table D10: Extended model using track in grade 9: average treatment effects conditional upon track choice

\begin{tabular}{llllccc}
\hline & \multicolumn{2}{c}{ No restrictions } & \multicolumn{2}{c}{ Only academic track } & \multicolumn{2}{c}{ No academic track } \\
& Coef. & St. error & Coef. & St. error & Coef. & St. error \\
\hline ATT & -0.010 & $(0.008)$ & -0.003 & $(0.006)$ & $-0.072^{*}$ & $(0.023)$ \\
ATNT & $0.048^{*}$ & $(0.010)$ & $0.037^{*}$ & $(0.012)$ & 0.027 & $(0.015)$ \\
ATE & $0.032^{*}$ & $(0.008)$ & $0.026^{*}$ & $(0.009)$ & 0.000 & $(0.013)$ \\
\hline
\end{tabular}

Note: Average treatment effects are calculated based on 111,571 students. Standard errors are corrected for clustering within the statistical sector and computed by sampling 250 draws from the estimated distribution. For each draw of the estimates we calculate the treatment effects by simulating the error terms of the potential outcome framework (100 draws for each student).

* Statistical significance at 5\% level. 
Table D11: Downgrading: estimation results semi-parametric approach

\begin{tabular}{|c|c|c|c|c|c|c|}
\hline \multirow[b]{3}{*}{ Variables } & \multirow{2}{*}{\multicolumn{2}{|c|}{$\begin{array}{l}\text { Selection equation } \\
\text { Index prop. score }\end{array}$}} & \multicolumn{4}{|c|}{ Outcome equation } \\
\hline & & & \multicolumn{2}{|c|}{ Baseline effect } & \multicolumn{2}{|c|}{ Difference if treated } \\
\hline & Coef. & St. error & Coef. & St. error & Coef. & St. error \\
\hline Relative distance & $0.131^{*}$ & $(0.004)$ & & & & \\
\hline Mother no high school ${ }^{a}$ & $-0.659^{*}$ & $(0.015)$ & $0.128^{*}$ & $(0.008)$ & $0.126^{*}$ & $(0.036)$ \\
\hline Mother high school $^{a}$ & $-0.406^{*}$ & $(0.010)$ & $0.100^{*}$ & $(0.007)$ & $0.049^{*}$ & $(0.023)$ \\
\hline No Dutch at home & $0.251^{*}$ & $(0.025)$ & -0.013 & $(0.013)$ & 0.001 & $(0.034)$ \\
\hline Low income & $-0.119 *$ & $(0.013)$ & $0.014^{*}$ & $(0.006)$ & 0.040 & $(0.023)$ \\
\hline Male & $-0.042^{*}$ & $(0.010)$ & $0.024^{*}$ & $(0.005)$ & $0.099^{*}$ & $(0.014)$ \\
\hline Repeated & $-0.496^{*}$ & $(0.018)$ & $0.023^{*}$ & $(0.008)$ & $0.240^{*}$ & $(0.039)$ \\
\hline Neighborhood characteristics & \multicolumn{2}{|c|}{ yes } & \multicolumn{2}{|c|}{ yes } & \multicolumn{2}{|c|}{ yes } \\
\hline P-value no observable heterogeneity & \multicolumn{2}{|c|}{0.000} & & & & \\
\hline P-value no unobservable heterogeneity & \multicolumn{2}{|c|}{0.913} & & & & \\
\hline Observations & \multicolumn{2}{|c|}{111,571} & & & & \\
\hline
\end{tabular}

Note: Standard errors are corrected for clustering within the statistical sector. The results are obtained from a semi-parametric approach which follows the approach described in Section 4.3 of Cornelissen et al. (2016) (pp. 55-56). The estimates of "Baseline effect" correspond to $\beta_{0}$ in their equation (26), while "Difference if treated" corresponds to $\beta_{1}-\beta_{0}$. The reported test statistic for observable heterogeneity tests for joint significance of all elements in the vector $\beta_{1}-\beta_{0}$, while the test for unobservable heterogeneity tests if MTEs differ with unobserved costs of treatment. We estimated the model in STATA with the userwritten command "mtefe" (Andresen, 2018).

* Statistical significance at $5 \%$ level.

${ }^{a}$ Base category $=$ mother has a degree in higher education. 


\section{Figure D3: Downgrading: MTE}

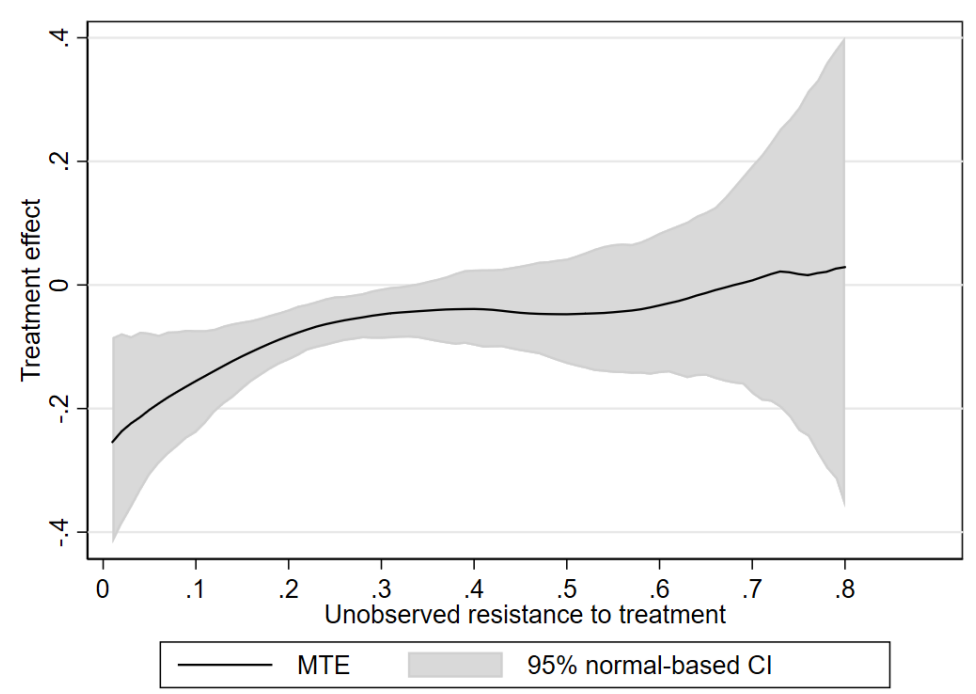

Note: MTEs are calculated based on 111,571 students using a local polynomial regression of degree 2 with an Epanechnikov kernel. Standard errors are computed with a bootstrap procedure (250 replications) and clustered within the statistical sector. P-value no observable heterogeneity (0.000), p-value no unobservable heterogeneity (0.913). 
Table D12: Downgrading: parametric approach

\begin{tabular}{|c|c|c|c|c|c|c|}
\hline \multirow[b]{3}{*}{ Variables } & \multirow{2}{*}{\multicolumn{2}{|c|}{$\begin{array}{l}\text { Selection equation } \\
\text { elite school }\end{array}$}} & \multicolumn{4}{|c|}{ Outcome equations } \\
\hline & & & \multicolumn{2}{|c|}{ elite school } & \multicolumn{2}{|c|}{ non-elite school } \\
\hline & Coef. & St. error & Coef. & St. error & Coef. & St. error \\
\hline Relative distance & $0.131^{*}$ & $(0.004)$ & & & & \\
\hline Mother no high school ${ }^{a}$ & $-0.659^{*}$ & $(0.015)$ & $0.628^{*}$ & $(0.033)$ & $0.378^{*}$ & $(0.016)$ \\
\hline Mother high school $^{a}$ & $-0.406^{*}$ & $(0.010)$ & $0.468^{*}$ & $(0.021)$ & $0.291^{*}$ & $(0.013)$ \\
\hline No Dutch at home & $0.251^{*}$ & $(0.025)$ & $-0.143^{*}$ & $(0.040)$ & 0.007 & $(0.023)$ \\
\hline Low income & $-0.119^{*}$ & $(0.013)$ & $0.107^{*}$ & $(0.023)$ & $0.046^{*}$ & $(0.012)$ \\
\hline Male & $-0.043^{*}$ & $(0.010)$ & $0.296^{*}$ & $(0.016)$ & $0.101^{*}$ & $(0.009)$ \\
\hline Repeated & $-0.497^{*}$ & $(0.018)$ & $0.467^{*}$ & $(0.036)$ & $0.106^{*}$ & $(0.015)$ \\
\hline Constant & $2.394^{*}$ & $(0.261)$ & $-1.744^{*}$ & $(0.275)$ & $-0.735^{*}$ & $(0.159)$ \\
\hline Neighborhood characteristics & \multicolumn{2}{|c|}{ yes } & \multicolumn{2}{|c|}{ yes } & \multicolumn{2}{|c|}{ yes } \\
\hline$\rho_{1}$ & -0.006 & $(0.040)$ & & & & \\
\hline$\rho_{0}$ & $0.123^{*}$ & $(0.034)$ & & & & \\
\hline Log likelihood & \multicolumn{2}{|c|}{-121935} & & & & \\
\hline Observations & \multicolumn{2}{|c|}{111,571} & & & & \\
\hline
\end{tabular}

Note: Standard errors are corrected for clustering within the statistical sector. The results are obtained from a parametric model where we assume that the error terms are jointly normally distributed. We estimated the model in STATA with the user-written command "switch_probit" (Lokshin and Sajaia, 2011).

* Statistical significance at $5 \%$ level.

${ }^{a}$ Base category $=$ mother has a degree in higher education. 